\title{
Ex Post Review and Expert Policymaking: When Does Oversight Reduce Accountability?*
}

\author{
John W. Patty ${ }^{\dagger} \quad$ Ian R. Turner ${ }^{\dagger}$
}

May 2019

\begin{abstract}
Ex post review is a common feature of policymaking institutions. We consider an environment in which an expert agent makes a policy recommendation, which can then be accepted or rejected by an overseer whose policy goals differ from those of the agent. The theory suggests that both behavior and optimal institutional design are sensitive to several factors, including actors' preference alignment, the importance of the policy decision, and the uncertainty about the correct policy choice. We characterize the types of situations in which ex post review creates incentives for the agent to make pathological policy choices. In these situations, ex post review can reduce accountability of the agent to overseer wishes and ultimately provide incentives to set aside review entirely. The theory also offers testable predictions about policy recommendations and the overseer's acceptance or rejection of these recommendations.
\end{abstract}

Keywords: Accountability; Oversight; Pandering; Policymaking; Bureaucracy

\section{Forthcoming, The Journal of Politics}

\footnotetext{
*We would like to thank Kris Ramsay, Ryan Hübert, Keith Schnakenberg, Andrea Aldrich, Nolan McCarty, Maggie Penn, Justin Fox and seminar participants at Texas A\&M, the University of Chicago, Yale University, and the Toulouse School of Economics for helpful discussions and comments throughout the development of this article. We also thank our anonymous reviewers and the editor for insightful feedback. Any and all errors are ours.

${ }^{\dagger}$ Professor of Political Science and Quantitative Theory \& Methods, Emory University. Contact: jpatty@emory.edu.

${ }^{*}$ Assistant Professor of Political Science, Yale University. Contact: ian.turner@yale.edu.
} 
Delegation, or giving an "agent" the authority to make choices on one's behalf, presents a classic and enduring dilemma in politics. Delegation potentially allows one to benefit from the agent's expertise while also providing an opportunity for the agent to exploit that expertise in pursuit of his or her own goals, potentially at the expense of one's own. ${ }^{1}$ In the end, unless one's agent is known to share one's own preferences, delegation creates an agency problem.

One commonly employed remedy for this agency problem is ex post review, in which the agent's decision must be approved by an overseer prior to going into force. The basic idea of ex post review is that, at the very least, it limits the agent's ability to make choices that are obviously counter to one's own interests. However, whenever delegation is beneficial because of the agent's superior information, ex post review will not eliminate the agency problem unless the agent's decision itself "levels the playing field" by revealing the agent's private information to the overseer.

In the United States federal government, ex post review is actively carried out in various forms within each of the three branches. Nearly all agency decisions are subject to judicial review, albeit according to standards that vary across both time and issue areas. In addition, since the late 1970s, the executive branch has developed its own ex post review procedures, the most visible of which is the requirement that many "significant" regulations be reviewed and approved by the Office of Information and Regulatory Affairs (OIRA). Finally, Congress carries out ex post review of bureaucratic policies through both annual appropriations and the Congressional Review Act of $1996 .^{2}$

Ex Post Review and "Crying Wolf." Regardless of who is reviewing the agent's decisions, ex post oversight is generally thought to enforce accountability. ${ }^{3}$ This raises the central question of this article: Why would anyone not assert their right to ex post review? Previous work has suggested that standard ex post veto institutions are superior to other options, such as gatekeeping (Crombez, Groseclose and Krehbiel, 2006). It is simultaneously well-documented that, as an example, Congress strategically weakens or outright precludes agency exposure to ex post oversight

\footnotetext{
${ }^{1}$ See Bendor and Meirowitz (2004), Gailmard and Patty (2012a,b), Miller (2005) for discussion of this dilemma.

${ }^{2}$ Pub.L. 104-121. Previously, CRA procedures had only been used to reverse Clinton Administration ergonomics standards in 2001 (Pub.L. 107-5), but the 115th Congress utilized the CRA to invalidate numerous agency rules.

${ }^{3}$ Within the canonical context of judicial review, Jaffe (1965) offers a seminal presentation of this view.
} 
(McCann, Shipan and Wang, 2016; Shipan, 1997). ${ }^{4}$ Why would ex post review be limited, or set aside, when it is thought to be integral for holding unelected bureaucrats accountable?

In this article we develop an argument that shows that ex post review can subvert the agent's incentives to make informed policy decisions in realistic environments. ${ }^{5}$ Through analysis of a formal model of policymaking we characterize under what conditions an overseer, with the power to review and invalidate the policy choices of an expert agent, would be better off if there were no ex post review. We provide an informational rationale for why insulating agents from review can improve accountability under certain circumstances. In the context of bureaucratic politics, the theory we develop provides insight into why courts tend to defer to agency determinations of both fact and statutory interpretation, ${ }^{6}$ and why Congress sometimes limits or precludes judicial review. ${ }^{7}$

Our setting is one in which an overseer with review powers can reject the agent's policy decision if the decision is observed by the overseer. In substantive terms, we consider a setting in which the agent can propose a large policy change, a moderate policy change, or no policy change at all. The overseer can reject any policy change, but if she does so, the result is no policy change at all. "Crying wolf" occurs in this setting when the agent proposes a large policy change when the agent would actually choose the moderate policy change if the overseer could not reverse the decision, but the overseer would reject a moderate policy change.

We show that when agent-overseer preferences are aligned ex post review is inconsequential from an accountability perspective. The agent pursues policy preferred by the overseer, leading to full deference. When agent-overseer preferences are extremely divergent ex post review is unambiguously beneficial. The agent never pursues policy change, a choice perfectly in line with overseer preferences. When agent-overseer preferences are moderately divergent the agent may cry wolf by pursuing extreme policy change when only moderate change is called for. In that case, the overseer may benefit from setting aside ex post review. This follows from a commitment problem for the overseer: the overseer cannot credibly commit ex ante to upholding moderate policy change even

\footnotetext{
${ }^{4}$ Case studies across several policy areas also provide evidence that Congress strategically anticipates the role of judicial review when crafting legislation (e.g., Cass, 1989; Melnick, 1983; Rose-Ackerman, 1995; Shipan, 2000).

${ }^{5}$ For two arguments about the possible costs of judicial review see Shapiro and Levy (1995) and Wagner (2012).

${ }^{6}$ Among many others, see Eskridge and Baer (2007), Hammond (2011), Meazell (2011), and Zaring (2010).

${ }^{7}$ For example, see McCann, Shipan and Wang (2016), Shipan (1997), and Smith (2005, 2006).
} 
though ex post she would prefer moderate policy change to being stuck with extreme change induced through crying wolf. The agent uses his informational advantage to leverage this commitment problem to avoid reversal by crying wolf and exaggerating the magnitude of policy change warranted by the facts on the ground. Insulating the agent from review when he may be crying wolf provides an institutional commitment to not intervening in moderate policy change, which can improve overseer welfare in those settings.

Crying wolf is an effective strategy for the agent when the overseer believes, ex ante, that it is relatively likely that extreme policy change is appropriate compared to moderate change. In these instances agents either engage in no policy change at all, when that is appropriate, or pursue extreme policy change when any policy change is called for. This dynamic in the theory provides a foundation for understanding how accountability mechanisms may promote 'over-regulation.' When policy environments are deemed to be highly risky in the sense that non-intervention may lead to large social and economic problems, which are not good politically for principals, agencies may respond by taking extreme regulatory measures even when they deem them over-reaching or believe that more moderate adjustments would have sufficed. They do this to avoid being reprimanded or having policies reversed when their principals (or, overseers) believe extreme measures are sufficiently likely to be more effective in light of the potential downsides. ${ }^{8}$

Crying wolf is also more likely to occur when the difference between the impacts of large and moderate policy changes is smaller. This is because the agent is not only motivated to avoid reversal: he is also motivated by policy and, accordingly, considers the degree of policy mismatch incurred by implementing a large policy change when only a moderate change is called for. While crying wolf becomes more likely as this difference shrinks, the cost this behavior imposes on the overseer declines as this difference gets smaller. Thus, the worst case from the overseer's perspective is when the difference between the two degrees of policy change is just small enough to induce the agent to cry wolf. In the situations in which the agent cries wolf the overseer may benefit from having her

\footnotetext{
${ }^{8}$ Enhanced air travel security is an illustrative example. Critics of enhanced security argue that the measures taken harm civil liberties while they do not significantly combat risks. Removing shoes and submitting to body scans are seen as policy overreactions. Our theory suggests that these measures are driven in part by the desire to drastically alter policy to insulate downside risks, which in this case are potentially large. Politicians believe that enhanced security is justified because it is likely enough that they are necessary. This in turn creates incentives for security agencies to pursue policies in line with those expectations to avoid rebuke from politicians that perhaps over-estimate their need.
} 
review powers set aside and yielding control over agent policymaking.

Crying Wolf and Accountability. Ex post review comes in many forms: elections, ${ }^{9}$ presidential vetoes, ${ }^{10}$ legislative and executive oversight, ${ }^{11}$ and judicial review. ${ }^{12}$ Previous research highlights how review can lead to policymaking pathologies, such as how elections can create perverse "pandering" incentives for reelection-seeking politicians. ${ }^{13}$ Specifically, if politicians are motivated by reelection then they may be induced to discard useful private information and instead choose policies they know are favored by the public independent of their private information (pandering), enact bold policies that their private information suggests are unlikely to yield positive benefits (posturing), or even continue on with policies that they know have failed or are failing (persistence). In all of these instances politicians disregard their superior private information and instead make choices that maximize the probability that they will remain in office.

In line with these, a common thread through the modern institutional theories of accountability is the finding that increased transparency can reduce accountability. ${ }^{14}$ For instance, Fox and Stephenson (2011) analyzes how judicial review impacts incentives for election-motivated politicians to posture in a political agency model. They show that the presence of ex post review can induce politicians to posture more often because review provides a 'bail-out effect.' Politicians are saved from having to bear the cost of ill-advised policy choices because an overseer will reverse those choices, which allows the politician to benefit from signaling without having to internalize the consequences. This is driven by voters' attempts to "screen" politicians, which can provide perverse incentives for low ability politicians to sometimes posture to 'act as if' they were high ability. ${ }^{15}$

We contribute to this existing work by focusing more squarely on a standard spatial model of policymaking, as opposed to the classical model of adverse selection in which the accountability mechanism is meant to sanction "bad types" of agents and reward "good types." Crying wolf is

\footnotetext{
${ }^{9}$ For a recent review of work on electoral accountability see Ashworth (2012).

${ }^{10}$ For example, Cameron (2000), and Groseclose and McCarty (2001).

${ }^{11}$ For example, Clinton, Lewis and Selin (2014), Gailmard (2009), and Wiseman (2009).

${ }^{12}$ The literature on analytical models of judicial review is large and growing. Among others, see Beim, Hirsch and Kastellec (2014), Bueno de Mesquita and Stephenson (2007), Callander and Clark (2017), Clark (2016), Fox and Stephenson (2015), Shipan (2000), Turner (2017, Forthcoming), and Vanberg (2001).

${ }^{13}$ On pandering, among others, see Canes-Wrone, Herron and Shotts (2001) and Gersen and Stephenson (2014).

${ }^{14}$ For example, Fox and Van Weelden $(2012,2015)$.

${ }^{15}$ See Bueno de Mesquita and Stephenson (2007) and Turner (2017) for similar effects of oversight on policymaking.
} 
similar to existing pandering pathologies in that it involves the agent disregarding policy-relevant information in pursuit of avoiding reputation costs. In contrast to Fox and Stephenson (2011) and related models, however, crying wolf is not driven by agents signaling their type. By crying wolf and signaling to the overseer that extreme policy change is called for the agent raises the stakes for the overseer to reverse his actions. In this article we examine under what circumstances an overseer with the power to invalidate agent policy choices would prefer to observe the policy proposed by an agent whose expertise, ability, and policy preferences are all known. In a spatial model of policymaking, when might accountability be harmed through greater control over agent's policy decisions?

The effects of transparency in this environment are interesting because, on the one hand, the overseer learns nothing about the agent from the agent's decisions (the overseer knows that the agent is an expert) but, at the same time, the overseer and agent have different preferences over policy. Transparency provides the overseer the ability to block policies that she does not like, but we presume that the agent is both motivated by the final policy outcome and does not like having his policy reversed. Thus, transparency can have two effects on the overseer's welfare.

First, transparency provides the overseer the opportunity to veto undesirable proposed policies, which has an unambiguously positive impact on her welfare, holding fixed the proposed policy. However, this ability to reject proposed policies can alter the agent's incentives and change the types of policies that the agent ultimately chooses. The impact of this second effect on the overseer's welfare is ambiguous. We show that, in a standard spatial setting, transparency can harm the overseer by inducing the agent to cry wolf by proposing more extreme policies than are justified.

These theoretical contributions combine insights from the aforementioned literature highlighting problems of over-accountability and the agency control literature exemplified by work like Bawn (1995) and Epstein and O'Halloran $(1994,1995) .{ }^{16}$ This earlier research focused primarily on how Congress might use administrative procedures to "stack the deck" in favor of preferred policy outcomes or how the ability to reject agency decisions ex post structured legislative incentives to expand or contract agency discretion or independence. We build on this existing work by connecting spatial policymaking with the accountability pathologies from the pandering literature. In contrast to

\footnotetext{
${ }^{16}$ See also, among many others, Epstein and O'Halloran (1999); Huber and Shipan (2002); McCubbins, Noll and Weingast (1987, 1989); McCubbins and Schwartz (1984).
} 
the studies cited above, we assume an expert agent already has discretion to make policy choices, but is subsequently reviewed by a political overseer who may disagree about the 'correct' choice. ${ }^{17}$ We combine both aspects of the policymaking process - spatial policymaking and accountability pathologies - into one tractable framework and characterize when and why ex post oversight institutions can reduce accountability. In turn, the results allow us to provide insight into when accountability may be improved by insulating the agency from ex post review entirely.

\section{The Model}

We analyze a two player, non-cooperative game between an expert agent, $A$, that makes policy choices and an overseer, $R$, that reviews agent policy choices. The agent is endowed with policyrelevant information and is directed by statute to make policy. The overseer is authorized to review and invalidate (or, block) the agent's policy choice and return policy to an exogenous status quo.

Informational Structure. The agent has an informational advantage in that he knows the true state of the world, denoted by $\theta \in \Theta=\{\delta,-1,0\}$, where $\delta<-1$, and the ex ante probability that the true state is $\theta$ is given by $p_{\theta}$. These three possible states of the world represent whether the facts on the ground justify extreme policy change $(\theta=\delta)$, moderate policy change $(\theta=-1)$, or maintenance of the status quo policy $(\theta=0)$. In other words, the magnitude of $\theta$ represents the agent's sincere expert opinion about how much policy change is warranted when making his policy decision. Once the agent observes $\theta$, he chooses policy, denoted by $x_{A} \in X=\mathbb{R}$. For instance, if the agent is a financial regulatory agency then $\theta$ might capture whether there are indicators of extreme market stress that require radical intervention to fend off financial crisis, there are worrying market fluctuations and some policy adjustments are deemed appropriate, or that markets are stable and the current regulatory regime seems to be working well.

Following the agent's choices, the overseer observes $x_{A}$ and then chooses to either uphold or reverse the agent's policy decision. This choice is denoted by $r \in\{0,1\}$ where $r=0$ means the

\footnotetext{
${ }^{17}$ This is in contrast to Epstein and O'Halloran (1994) and Epstein and O'Halloran (1995). Both papers introduce an ex post veto, but in the former there is no expert agent: information about the policy environment is publicly revealed prior to review. In the latter, information is private but an interest group chooses whether to reveal that information. In our model the agent is expert (he alone receives policy-relevant information prior to review) relative to the overseer unless he, himself, chooses to reveal that information (rather than a third-party doing so).
} 
overseer upholds agent-made policy and $r=1$ means she rejects the agent's choice. If the overseer reverses the agent, then the final policy is set at $x=0 .{ }^{18}$ If the overseer upholds the agent's decision, then the final policy is $x=x_{A}$. This can be thought of as a court or perhaps Congress weighing in on whether an agency's interventions in financial markets are justified, desirable, or otherwise consistent with the overseer's prevailing ideology regarding government intervention in markets.

Preferences. The agent is motivated by two main factors: (1) he wants policy to match the true state $(x(\theta)=\theta)$, and (2) he wants to have his policy choice upheld by the overseer $\left(r\left(x_{A}\right)=0\right)$. If the agent is reversed by the overseer, he internalizes a cost $k>0$.This cost is exogenous and common knowledge. This could be a reputational cost, an opportunity cost, or direct costs such as a fine or demotion. Understanding $k$ as a reputational cost also lends itself to an indirect measure of agency independence if one conceives of independence as inversely proportional to the agency's cost of reversal. Overall, this represents a situation in which the agent is "faithful" in the sense that he wants policy to match the state with no distortions due to preference or ideology. Substantively, this proxies an environment in which the agent is motivated by the policy area in the purest sense. Continuing the example of financial regulation, the agent could represent an agency that sincerely seeks to balance consumer protection and economic growth by intervening in the financial markets only when it deems it necessary to maintain market stability. In contrast, the overseer may differ in where she would like policy to be realized. This could represent a political or ideological agenda or, more generally, an ex ante "bias" as to what policy is most desirable given the current policy environment $(\theta)$. This bias is captured by the exogenous and common knowledge parameter $\beta \geq 0$.Accordingly, the payoffs for the overseer and agent are given by the following expressions:

$$
\begin{aligned}
& u_{R}(x, r)=-(\theta+\beta-(1-r) x)^{2}, \\
& u_{A}(x, r)=-(\theta-(1-r) x)^{2}-r k .
\end{aligned}
$$

\footnotetext{
${ }^{18}$ For simplicity, we do not allow the overseer to directly set policy. This is an accurate portrait of ex post review of many decisions. For an empirical justification of this assumption in the context of judicial review in the US, see Wagner (2012). We consider a modified version of this setting in which the overseer can request further justification of the policy prior to making an up-or-down decision in Section 3.2.
} 
These utility functions formalize the discussion above and imply that the overseer wants policy to be as close as possible to her ideal point $(x=\theta+\beta)$ and the agent wants the final policy $x$ to match the state $(x=\theta)$ and be upheld by the overseer to avoid paying reversal cost $k$.

Substantively, overseer-agent preference disagreement can be conceptualized as divergent beliefs or evaluations of risk. In terms of financial regulation, there are fundamentally different beliefs about how stable financial markets are, and how government intervention may affect market stability. In the terms of our model, the overseer represents a political actor that believes markets are relatively stable compared to the agent. This is reflected by the fact that the overseer's state-conditioned ideal point calls for less policy change than the agent. That is, due to divergent beliefs about how government intervention will affect financial market stability the agent prefers more government intervention in markets than the overseer.

Strategies and Beliefs. We denote the agent's policy strategy as $s_{A}(\theta): \Theta \rightarrow \Delta(X)$, which maps states of the world into probability distributions over policy choices. The overseer's review strategy is a mapping from policy choices into a probability of reversal, $s_{R}(x): X \rightarrow[0,1]$, where $s_{R}\left(x_{A}\right)$ denotes the probability that the overseer reverses policy $x_{A}$. The overseer's beliefs are denoted by $b_{R}(x): X \rightarrow \Delta(\Theta)$ where $\Delta(\Theta)$ represents the set of probability distributions over $\Theta .{ }^{19}$

\section{Equilibrium}

Our equilibrium notion is perfect Bayesian equilibrium, which requires (1) that the overseer have correct beliefs about the state after observing the agent's policy choice, and (2) that the agent and overseer each act so as to maximize their subjective expected payoffs.

The first question we address is how the overseer should respond if the agent sets policy "truthfully.” In formal terms, the agent's truthful strategy corresponds to behavior in a separating equilibrium and is represented as follows:

$$
s_{A}^{\text {truthful }}(\theta)=\theta
$$

Truthful policymaking by the agent is a normative benchmark, especially insofar as the agent has been delegated authority to make policy decisions because of his information or expertise. Given

\footnotetext{
${ }^{19}$ Given the sequential nature of the game and the informational structure, the agent's beliefs are trivial and omitted.
} 


\begin{tabular}{|c|c|c|c|}
\hline $\begin{array}{c}\text { Policy Choice } \\
\text { \& True State }\end{array}$ & $\begin{array}{c}\text { Aligned } \\
\text { Preferences }\end{array}$ & $\begin{array}{c}\text { Moderate } \\
\text { Preferences }\end{array}$ & $\begin{array}{c}\text { Extreme } \\
\text { Preferences }\end{array}$ \\
\hline$x, \theta$ & $\beta \leq 1 / 2$ & $\beta \in\left(1 / 2,-\frac{\delta}{2}\right]$ & $\beta>-\frac{\delta}{2}$ \\
\hline$x=\theta=0$ & $r=0$ & $r=0$ & $r=0$ \\
$x=\theta=-1$ & $r=0$ & $r=1$ & $r=1$ \\
$x=\theta=\delta$ & $r=0$ & $r=0$ & $r=1$ \\
\hline
\end{tabular}

Table 1: Overseer's Best Response to Truthful Policymaking, Conditional on $\beta$.

that the overseer believes that the agent is setting policy truthfully as described by $s_{A}^{\text {truthful }}$, her best response, given $\beta$, is summarized in Table 1 .

Table 1 illustrates that, as the overseer's and agent's preferences diverge (i.e., as the bias, $\beta$, grows), it becomes more difficult for the agent to be upheld following truthful policymaking. Based on the regions identified in Table 1, and to ease the presentation, we refer to the overseer as having aligned preferences if $\beta \leq \frac{1}{2}$, moderate preferences if $\beta \in\left(\frac{1}{2},-\frac{\delta}{2}\right]$, and extreme preferences if $\beta>-\frac{\delta}{2}$.

Returning to financial regulation, these regions can represent overseer and agent preferences over government intervention. The agent pursues regulation pragmatically: no new regulation is needed when $\theta=0$, when $\theta=-1$ there may be signs of instability and the agent would like to shift financial policy to stabilize it, and when $\theta=\delta$ the agent supports extreme policy interventions to stem potentially calamitous market failures. When preferences are aligned the overseer agrees with the agent's assessments and, accordingly, will always uphold agent-preferred regulation. Both players take a pragmatic approach to regulation: it can be beneficial or unnecessary depending on the environment. On the other extreme, when policy disagreement is large the overseer will reject any attempt to further regulate financial markets. This could represent a strong ideological commitment to deregulation. Finally, when there is moderate policy disagreement, and the agent pursues policies based upon his expert assessment of market stability, the overseer allows no intervention and extreme intervention when called for, but blocks moderate market intervention. In this case the overseer is willing to sign off on market interventions when the downside risk is very great, but is otherwise skeptical of the efficacy of regulation for market stabilization in less extreme circumstances.

Given the overseer's best response to truthful policymaking when she has either moderate or extreme preferences (i.e., $\beta>1 / 2$ ), the agent will not set policy truthfully in equilibrium. When $\theta=-1$, 
truthful policymaking will lead to reversal. Due to this, when $\theta=-1$, choosing $x_{A}=0$ necessarily increases the agent's expected payoff by $k$. This is because reversal leads to the same policy outcome as if the agent had chosen $x_{A}=0$. When $\theta=\delta$ and the principal has either aligned or moderate preferences the agent will set policy truthfully since this will lead to being upheld. However, when the principal has extreme preferences the agent would again benefit from setting $x_{A}=0$, rather than truthfully setting policy, to avoid reversal. Thus, when the principal has either moderate or extreme preferences and $\theta=-1$ the agent would rather deviate from truthful policymaking and set $x_{A}=0$ to avoid reversal and when $\theta=\delta$ the agent would rather deviate from truthful policymaking only when the principal has extreme preferences. This immediately leads to the following proposition.

Proposition 1 If the reversal cost is positive $(k>0)$, then there is a truthful separating equilibrium in which the agent always matches policy to the state $\left(s_{A}^{*}(\theta)=\theta\right)$ if and only if the overseer has aligned preferences (i.e., $\beta \leq 1 / 2$ ). Moreover, if the principal has extreme preferences (i.e., $\beta>-\frac{\delta}{2}$ ) then, in any equilibrium, the agent pools by choosing $x_{A}=0$ for all values of $\theta$.

The conclusion that a truthful separating equilibrium exists only when the overseer has aligned preferences implies that the overseer can get completely responsive policymaking when her preferences are sufficiently close to those of the agent. ${ }^{20}$ This is not true when the overseer has extreme preferences. In that case the agent invariably sets $x_{A}=0$ to avoid reversal, implying a pooling equilibrium in which the agent is completely unresponsive to his information. Proposition 1 implies that the overseer can be harmed by ex post review only if she has moderate preferences.

\subsection{Moderate Preference Divergence: Two Cases}

In deriving the equilibrium behaviors of the overseer and agent, there are two regions of the parameter space, depending on the value of the extreme state, $\delta$. The first region is that in which $\delta$ is relatively moderate: $-2 \leq \delta<-1$. We refer to this case as that of a low urgency issue: in this region, the difference between the extreme and moderate states of nature is relatively small. The second, complementary, region is that in which $\delta$ is large in absolute value: $\delta<-2$. We refer to this region

\footnotetext{
${ }^{20}$ As with many signaling models, there are multiple equilibria if the cost of reversal, $k$, is sufficiently large. In order to keep our analysis as tight as possible, however, we will presume that the agent plays the truthful separating strategy whenever it is supportable in equilibrium.
} 


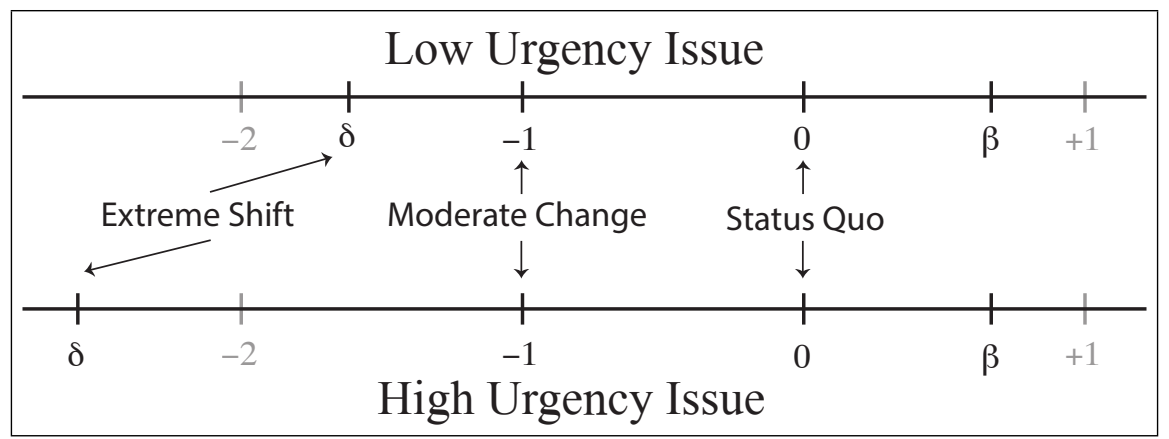

Figure 1: Two Cases of Policy Urgency

as that of a high urgency issue. In this region, the difference between extreme and moderate states of nature is larger: it is more important to both players that the agent's policymaking distinguish between these two situations. We refer to this distinction as the urgency of the "issue" because the absolute value of $\delta$ is proportional to how much disutility both players will incur from not changing the status quo policy of $x=0$ when $\theta=\delta$. The two cases are illustrated in Figure 1.

Low and high urgency issues are distinguished by the magnitude of their potential downsides. In terms of economic regulation, low urgency and high urgency issues can be differentiated by the severity and persistence of market downturns. The continuum from low to high urgency issues reflects short recessions to large-scale market collapse. As concrete examples, the economic fundamentals underlying the Global Financial Crisis in 2008 represent high urgency issues while those underlying the recession in the early 2000's are relatively lower urgency, though both were more extreme than moderate market distortions. The Great Recession lasted for approximately 18 months with peak unemployment reaching $10 \%$ and a 5.1\% decline in GDP while the "dot-com" recession lasted around 8 months with peak unemployment of $6.3 \%$ and only a $0.3 \%$ GDP decline. Both situations represent relatively large losses, but the former was clearly more extreme than the latter.

\subsection{High Urgency Issue}

In the high urgency issue case $(\delta<-2)$, the agent would prefer to obfuscate after observing $\theta=-1$ by choosing $x_{A}(-1)=0$. The extreme policy is too extreme for the agent to find it profitable to pursue, even though it would be upheld, when the true state calls for moderate policy change. The following proposition characterizes equilibrium behavior in this case. ${ }^{21}$

\footnotetext{
${ }^{21}$ For results involving agent obfuscation we set the overseer's off-the-equilibrium-path beliefs upon observing $x_{A}=$ -1 to $\operatorname{Pr}[\theta=-1 \mid x=-1]=1$. This implies that the overseer believes the agent is being "sincere" when he sets $x_{A}=-1$.
} 
Proposition 2 If the issue is high urgency $(\delta<-2)$ and the overseer has moderate preferences $\left(\beta \in\left(\frac{1}{2},-\frac{\delta}{2}\right]\right)$, then there is a semi-pooling equilibrium in which the agent chooses $x_{A}=0$ when $\theta \in\{-1,0\}$, chooses $x_{A}=\delta$ when $\theta=\delta$, and the overseer upholds $x_{A} \in\{\delta, 0\}$ and reverses $x_{A}=-1$.

While this equilibrium does involve agent obfuscation, it runs counter to crying wolf behavior. The agent appeases the overseer by maintaining the status quo, which is in line with the overseer's induced preferences, rather than crying wolf and acting as if extreme policy change is called for. The threat of reversal drives the agent to forego pursuit of any policy change at all. ${ }^{22}$ In order to be upheld the agent must choose either the high urgency extreme policy or no policy change at all when the state is moderate. In this case he incurs spatial policy losses either way, but the losses associated with $x=0$ are smaller and therefore are more easily offset by the benefits of being upheld. We will see below that, when facing a high urgency issue, the overseer always benefits from ex post review. This is because the equilibrium described in Proposition 2 involves the agent choosing the overseer's preferred policy in all states. The presence of ex post review polarizes policy choices so that there are only extreme policy overhauls or maintenance of the status quo when issues are high urgency.

From an empirical standpoint, this dynamic represents situations in which we should observe little to no policy change until extreme policy change is the appropriate response to the facts on the ground. Landmark civil rights policies implemented in the mid-twentieth century are examples of issue areas of this sort. Prior to these profound shifts in policy there was reason to think that some policy change would be beneficial for myriad reasons, but also that such change would not withstand judicial review. ${ }^{23}$ There was little policy change from Reconstruction until the 1950s and 1960s. Eventually civil rights legislation garnered sufficient political support and was then implemented over time, in some cases through extreme policy instruments (e.g., mandatory busing programs). This followed evolution in the political environment such as escalation of social and political unrest,

\footnotetext{
${ }^{22}$ This is similar to results in Bueno de Mesquita and Stephenson (2007) and Turner (2017) in which judicial review can deter agencies from regulating at all or investing effort toward implementation, respectively.

${ }^{23}$ There is significant reason to believe that judicial oversight played a role in stymieing progress. In the periods following Reconstruction the judiciary consistently struck down policies seeking to extend equal protection under the 13th and 14th amendments to the states and/or private actions (see, for example, US v. Cruikshank, 92 U.S. 542 (1875), the Civil Rights Cases, 109 U.S. 3 (1883) striking down the Civil Rights Act of 1875, and Plessy v. Ferguson, 163 U.S. 537 (1896)). Generally, these judgments limited progress on civil rights until at least Brown v. Board of Education of Topeka, 347 U.S. 483 (1954) and landmark legislation such as the Civil Rights Act of 1964, the Voting Rights Act of 1965, and the Civil Rights Act of 1968.
} 
increasingly visible violence, and shifts in public sentiment over the issue. ${ }^{24}$ Put simply, this period was characterized by sustained commitments to the status quo followed by substantial shifts with very little in the way of intermediate policy adjustments along the way.

\subsection{Low Urgency Issue}

In a low urgency issue $(\delta \in[-2,-1))$, the agent strictly prefers $x=\delta$ to $x=0$ when $\theta=-1$, so that, for any $k>0$, the agent strictly prefers obfuscating when $\theta=-1$ by choosing $x_{A}=\delta$. In contrast with the high urgency case, the agent prefers to incur the policy disutility of $(\delta+1)^{2}$ rather than -1 in order to avoid reversal. However, this type of obfuscation by the agent can be upheld with certainty (i.e., "deferred to") in equilibrium only if the probability of an extreme state $(\theta=\delta)$ is sufficiently high relative to the probability of the moderate state $(\theta=-1)$, as described in the following proposition.

Proposition 3 If the issue is low urgency $(\delta \in[-2,-1))$, the overseer has moderate preferences $\left(\beta \in\left(\frac{1}{2},-\frac{\delta}{2}\right]\right)$, and

$$
\frac{p_{-1}}{p_{\delta}+p_{-1}} \leq \frac{\delta+2 \beta}{2(1+\delta)}
$$

then there is a semi-pooling equilibrium in which the agent chooses $x_{A}=\delta$ for both $\theta \in\{\delta,-1\}$ and $x_{A}=0$ for $\theta=0$, and the overseer upholds $x_{A} \in\{\delta, 0\}$ and reverses $x_{A}=-1$.

The threshold for $p_{-1}$ in inequality (1) constrains the probability of the moderate state $\left(p_{-1}\right)$ relative to that of the extreme state $\left(p_{\delta}\right)$. Inequality (1) is based upon the sequential rationality of the overseer: if the probability of the moderate state is too high relative to that of the extreme state, then the overseer can not rationally defer to the extreme policy, because it is too likely that such a policy indicates that the true state is that demanding a moderate policy change - which the overseer wants to reverse given the presumption that she has moderate preferences. If the probability of a moderate state, $p_{-1}$, is too large relative to that of an extreme state, $p_{\delta}$, then this type of equilibrium must involve mixing by the overseer and agent, described in the following proposition.

\footnotetext{
${ }^{24}$ Of course, there was a long history of violence suppressing civil rights prior to the mid-20th century. There were many other factors that led to change when it did, but the increasing unrest, particularly as it became more visible from technological advances (e.g., television), contributed to increased support for changes.
} 
Proposition 4 If the issue is low urgency $(\delta \in[-2,-1))$, the overseer has moderate preferences $\left(\beta \in\left(\frac{1}{2},-\frac{\delta}{2}\right]\right)$, and inequality (1) does not hold, then there is a semi-pooling equilibrium in which the agent chooses chooses $x_{A}=\theta$ for $\theta \in\{0, \delta\}$, and, when $\theta=-1$, chooses $x_{A}=\delta$ with probability $\frac{p_{\delta}(2 \beta+\delta)}{p_{-1}(\delta-2 \beta+2)}$, and $x_{A}=0$ with probability $1-\frac{p_{\delta}(2 \beta+\delta)}{p_{-1}(\delta-2 \beta+2)}$. The overseer upholds $x_{A}=0$, reverses $x_{A}=-1$, and upholds $x_{A}=\delta$ with probability $\frac{k}{-\left(2 \delta+\delta^{2}\right)+k}$.

Taken together, Propositions 3 and 4 provide a theoretical basis for understanding the crying wolf phenomenon. In these cases the agent chooses to obfuscate by pursuing more extreme policy change than is warranted by his information. The agent is driven to avoid being reversed by the overseer and chooses between foregoing policy change or choosing an extreme policy change when the state calls for moderate change. Since the extreme policy in this case is closer to the moderate state than in the high urgency case the agent is better off limiting his spatial policy losses and avoiding reversal by crying wolf compared to either sincerely pursuing moderate change when it is called for, which will lead to certain reversal, or instead appeasing the overseer by choosing $x_{A}=0$ when $\theta=-1$.

When extreme policy change is more likely to be called for than moderate change (as in Proposition 3 ) this is a highly effective strategy. Crying wolf leads to the agent being upheld with certainty. When the moderate state is sufficiently likely relative to the extreme state (as in Proposition 4) crying wolf is still effective, however in equilibrium there is still a positive probability that the agent will be overturned for setting extreme policy $\left(x_{A}=\delta\right)$. Due to this, the agent also sometimes appeases the overseer by foregoing any policy change in the moderate state and being upheld with certainty. That is, the agent mixes so that he can offset the positive probability of being reversed following $x_{A}=\delta$ by ensuring he is upheld with certainty when he instead chooses $x_{A}=0$. In both of these environments the agent is induced to cry wolf with his policy choices to reduce the likelihood of being reversed while still doing his best to preserve the integrity of his policy choices.

From the perspective of the overseer, this can lead to ex post review harming her own utility. She systematically prefers less policy change than the agent but in these crying wolf equilibria the agent is being induced to exaggerate the extremity of the policy environment by choosing $x_{A}=\delta$ when in fact moderate change was called for $(\theta=-1)$ even though, ex post, both actors would prefer the agent to have pursued moderate policy change when it was called for. 
For instance, in these environments a financial regulatory agency pursues more extreme interventions in financial markets than market conditions justify. Such an action 'ups the ante' for the overseer: if the agency is reversed following extreme market intervention and it turns out that policy was called for then the overseer may be indirectly allowing a relatively severe downturn in financial markets. This makes crying wolf effective as a means to avoid reversal, which, in turn, creates a sort of 'buyer's remorse' for the overseer. In retrospect, the overseer would be better off had she allowed the agency to more moderate market regulation. This possibility - that oversight induces the agency to pursue strategic over-regulation - opens the door for the overseer to be made better off by having her institutional review powers set aside.

\section{Incentives for Institutional Design}

When would the overseer benefit from setting aside ex post review? What is the impact of allowing the overseer to request justification of a policy prior to choosing whether to reverse it? The answers to these question jointly imply that ex post review should be set aside when (1) an extended review process is not feasible, (2) the overseer's preferences are similar to those of the agent, and (3) the extreme state of nature is relatively likely.

\subsection{When is Ex Post Review Beneficial?}

If we suppose that the overseer could publicly commit ex ante to not reviewing the agent's policy decision, then the agent's optimal strategy would be truthful policy making $\left(s_{A}^{\text {truthful }}(\theta)=\theta\right)$. The overseer's expected payoff from committing to not review the agent's decision is accordingly $V_{R}^{\text {No Review }}=-\beta^{2}$. We now consider whether the overseer would prefer this to the best payoff she can obtain in equilibrium. ${ }^{25}$

Aligned Preferences: Ex Post Review is Irrelevant. When the overseer's preferences are aligned with the agent's $(\beta \leq 1 / 2)$, the overseer will always approve the agent's state-conditioned most preferred policy, so that there is a truthful separating equilibrium. Ex post review yields the overseer an equal equilibrium payoff to what she would receive in the absence of ex post review: such review

\footnotetext{
${ }^{25}$ In line with our analysis throughout the article, we do not consider every possible equilibrium. For example, there is always an equilibrium in which the overseer reverses every policy decision except $x_{A}=0$, and the agent always chooses $x_{A}=0$ (of course, this is the only equilibrium outcome when $\beta>-\delta / 2$ ).
} 
is irrelevant from the overseer's perspective when preferences are sufficiently aligned. ${ }^{26}$ This is a classic point in models of this sort: when preferences are similar pathological agency problems are of minimal concern. Indeed, in this case the perverse incentives discussed in the previous section do not manifest at all. There is no reason for the overseer to set aside review.

Extreme Preferences: Ex Post Review is Beneficial. The overseer always benefits from ex post review if her preferences are extreme $\left(\beta>-\frac{\delta}{2}\right)$. This follows from the fact that the agent sets the overseer's preferred choice, $x_{A}=0$, in equilibrium: the threat of being overturned leads the agent to choose $x_{A}=0$ even though, in equilibrium, the overseer never actually has to exercise this power. ${ }^{27}$ Accordingly, in this environment the overseer never benefits from yielding this institutional threat. Coupled with our discussion of aligned preferences above, this implies the overseer can have a strict preference to set aside ex post review only if her preferences are moderate.

\section{Moderate Preferences}

When the overseer has moderate preferences $\left(\beta \in\left(\frac{1}{2},-\frac{\delta}{2}\right]\right)$, the impact of ex post review on the overseer's welfare depends on the urgency of the issue, $\delta$. We begin with high urgency issues.

High Urgency Issues: Ex Post Review is Beneficial. When the issue is high urgency $(\delta<-2)$, Proposition 2 implies that, even if the overseer has moderate preferences, she will prefer to retain ex post review. This is because the agent's obfuscation in this case (namely, choosing $x_{A}=0$ when $\theta=-1$ ) is what the overseer would prefer the agent do. This reflects a situation in which the agent's interests are sufficiently aligned with the overseer so that the prospect of ex post review induces the agent to choose the policy that the overseer prefers chosen. In other words, the agent is unwilling to subvert the overseer's intentions by crying wolf because that level of policy change is too extreme.

From an empirical standpoint, this implication of the model can be interpreted as follows: the overseer will seek to retain ex post review whenever the urgent policy change is sufficiently extreme. The key characteristic of policies in this scenario are those in which the policy change called for by the significant threat is "too extreme a remedy," relative to doing nothing, when a moderate policy response is called for. Examples of policy areas in which this is the case include issues involving

\footnotetext{
${ }^{26}$ Formal derivations for all the welfare results can be found in the proof of Proposition 5 in the online appendix.

${ }^{27}$ This dynamic is reminiscent of classic agenda-setting results (Romer and Rosenthal, 1978).
} 
individual liberties. For example, a court might uphold quarantining citizens without due process during a massive, life-threatening health crisis, but not uphold mandatory vaccinations against a significant, but not extreme health threat. So long as the health authorities prefer the status quo policy to ordering a quarantine against the moderate public health threats, the court can defer to the government when a quarantine is ordered. ${ }^{28}$

Low Urgency Issues: Welfare When the Agent Cries Wolf. When issues are low urgency, overseer preferences about review depend on the relative likelihoods of the moderate and extreme states. Extreme State Relatively Likely: Ex Post Review is Always Harmful. If the extreme state is sufficiently likely (i.e., inequality (1) holds), then the overseer prefers to set aside ex post review. If the agent sets policy in an insincere fashion, he is setting policy farther away from the overseer's (state-conditional) ideal point than he would have absent review. This is intuitive once one interprets $p_{-1}$ as "the state that the overseer would like to control policy in" and notes that, when inequality (1) is satisfied, the overseer is getting a strictly worse policy outcome in the presence of ex post review than she would get if there were no review. Thus, if the agent is crying wolf and being upheld with certainty by the overseer, then the overseer would strictly benefit from setting aside ex post review.

This conclusion is robust in the sense that it is generally invariant to small changes in the parameters of the situation $(\beta, p$, and $\delta)$. Ex post review can hurt the overseer through inducing the agent to set extreme policy to avoid reversal. When the extreme state is sufficiently likely, the agent can do this without fear of reversal because the overseer can not commit to reversing the extreme policy. This is akin to the situation discussed above in which large-scale regulatory interventions in financial markets signal that the downside risk is a serious recession if the agency is not allowed to intervene. The overseer is forced to uphold in this scenario due to the magnitude and relative likelihood of the downside risk, which can only harm her from an ex ante welfare perspective.

Extreme State Relatively Unlikely: Ex Post Review is Sometimes Harmful. If the extreme state is sufficiently unlikely (inequality (1) is not satisfied), then the agent mixes between appeasing the overseer and crying wolf, and the overseer upholds $x_{A}=\delta$ probabilistically. In this scenario the

\footnotetext{
${ }^{28}$ Similar examples include upholding curfew orders during periods of public disorder but rejecting attempts to preempt public demonstrations during periods of political or social unrest.
} 
overseer benefits from setting aside ex post review if and only if,

$$
\delta p_{\delta}(2 \beta+\delta)+p_{-1}(1-2 \beta) \geq 0
$$

Inequality (2) is not always satisfied given the restrictions on $\beta$ and $\delta$ in this environment. When the agent mixes between crying wolf $\left(x_{A}(-1)=\delta\right)$ and appeasing the overseer $\left(x_{A}(-1)=0\right)$ ex post review can either benefit or harm the overseer. In contrast to the "pure crying wolf" environment in which ex post review is always harmful, in this case there are countervailing welfare effects. Sometimes the overseer will uphold the agent when he was crying wolf or reverse the agent when he was not crying wolf but instead chose the extreme policy sincerely, which harms the overseer's welfare. At other times she will reverse the agent when he was crying wolf or uphold him when he was setting policy sincerely, which benefits her welfare.

In substantive terms, sometimes the overseer steps in to block extreme financial market interventions when they were called for, causing large market downturns, while at other times she allows extreme regulatory intervention when true market conditions did not justify such an intervention. On the other hand, sometimes she is able to block extreme market regulation when the agency was crying wolf and uphold radical market intervention when markets were highly volatile, stemming potential financial crises. Which mix of market conditions and regulatory choices obtain dictates whether or not ex post review is beneficial. Thus, whether the overseer prefers to retain or set aside ex post review depends on the parameters of the problem in this environment. Taken together, the preceding analysis leads to the following proposition.

Proposition 5 From an ex ante welfare perspective, ex post review affects the overseer as follows:

1. When the overseer has aligned preferences ex post review is irrelevant,

2. When the overseer has extreme preferences ex post review is beneficial,

3. When the overseer has moderate preferences ex post review is harmful if and only if extreme states are of low urgency and (i) the agent always cries wolf (i.e., inequality (1) is satisfied) or (ii) the agent cries wolf probabilistically (i.e., inequality (1) is not satisfied) and $\delta p_{\delta}(2 \beta+$ 


$$
\delta)+p_{-1}(1-2 \beta) \geq 0 \text { (i.e., inequality (2) is satisfied). }
$$

Proposition 5 shows that ex post review is only harmful when the overseer has moderately biased preferences and issues are low urgency. As discussed above, when the agent cries wolf probabilistically whether the overseer benefits from setting aside ex post review depends on the parameters in inequality (2). We conclude our welfare analysis by exploring how the likelihood the overseer prefers setting aside review varies in the relative magnitude of preference disagreement, the probability that extreme policy change is called for relative to moderate changes, and in the relative urgency of the issue area given that we are in a policymaking environment characterized in Proposition 4: moderate preference divergence, low urgency issues, and inequality (1) not satisfied.

First, consider how the likelihood that ex post review harms overseer welfare varies as a function of her bias. Note that inequality (2) is always satisfied for $\beta=1 / 2: \delta p_{\delta}(1+\delta)>0$. This implies that, for sufficiently small $\beta>1 / 2$, the overseer would strictly prefer to abstain from ex post review. Conversely, for $\beta=-\frac{\delta}{2}$, we have that $p_{-1}(\delta+1)<0$, so that, for sufficiently large $\beta<-\frac{\delta}{2}$, the overseer would strictly prefer to retain ex post review. Thus, if the overseer has preferences that are similar enough to those of the agent, the overseer is more likely to prefer ruling out ex post review of the agent's decision (i.e., not see $x_{A}$ ). In contrast, it is more likely she benefits from maintaining ex post review when $\beta$ is large enough (i.e., when the overseer is sufficiently biased). This leads to the following intuitive prediction: Ex post review is more likely to be set aside when the overseer has preferences relatively more aligned with the agent.

Holding $\delta$ and $\beta$ constant, inequality (2) is less likely to be satisfied for larger values of $p_{-1}$ and more likely to be satisfied for larger values of $p_{\delta}$, because $\delta(2 \beta+\delta)>0>1-2 \beta$. This leads to the following prediction: Ex post review is more likely to be set aside when the probability of the extreme state increases and/or the probability of the moderate state decreases. The probability that the agent cries wolf when the moderate state obtains is increasing in $p_{\delta}$ and decreasing in $p_{-1}$, while, simultaneously, changes in these probabilities do not impact the overseer's review strategy when $x_{A}=\delta$ (per Proposition 4). This implies that the countervailing welfare effects discussed above shift asymmetrically. The probability the overseer wrongfully upholds crying wolf increases since the agent is crying wolf with a higher probability, thereby harming overseer welfare and making it more 
likely that she benefits from setting ex post review aside.

Finally, because $\delta(2 \beta+\delta)>0$ in this parameter region, it follows that inequality (2) is more likely to be satisfied for larger absolute values of $\delta$. This comparative static only holds for low urgency issues. That is, among low urgency issues, ex post review is more likely to be set aside for issues of relatively higher urgency (larger absolute values of $\delta$ ). Note that this comparative static is "strict" only when the extreme state is relatively unlikely (in the sense of Proposition 4). From a qualitative perspective, this prediction is relevant for situations in which, in the presence of ex post review, the agent will be reversed with positive probability. As noted above, in this region ex post review imposes two costs on the overseer. The first cost occurs when the overseer does not reverse the agent but he cried wolf and set overly extreme policy (e.g., the regulatory agency is upheld for extreme financial market regulation even though market conditions did not require such intervention). The second occurs when the overseer does reverse the extreme policy but the agent was not crying wolf (e.g., financial market conditions did call for extreme intervention to forestall a severe market downturn, but the regulatory agency was blocked from taking action).

All of the preceding analysis is summarized in Figure 2. The figure illustrates the conclusion from this section's analysis that the institutional incentives identified are at their most "binding" in one region: when the overseer's preferences are moderately divergent from those of the agent and the issue is of moderate urgency. Thinking for a moment about the delegation problem from an empirical standpoint, this is more restrictive in appearance than in reality. When the overseer's policy preferences are extremely divergent from those of the agent, ex post review is beneficial because it neutralizes the agent: the agent never proposes policy change. In such a case, one would never see review of the agent's decisions (indeed, one might never observe the agent making any decisions at all). It is arguable that delegation has not really occurred (in equilibrium, that is). Similarly, when preferences are aligned, ex post review is irrelevant, because the overseer and agent know that no review is necessary: the overseer might as well simply hand absolute authority to the agent.

Thus, the interesting distinction in Figure 2 is that of issue urgency when preferences are moderately divergent. To summarize: our theory indicates that ex post review is harmful to the overseer when the extreme state is more likely to be warranted, because the agent is more likely to cry wolf 


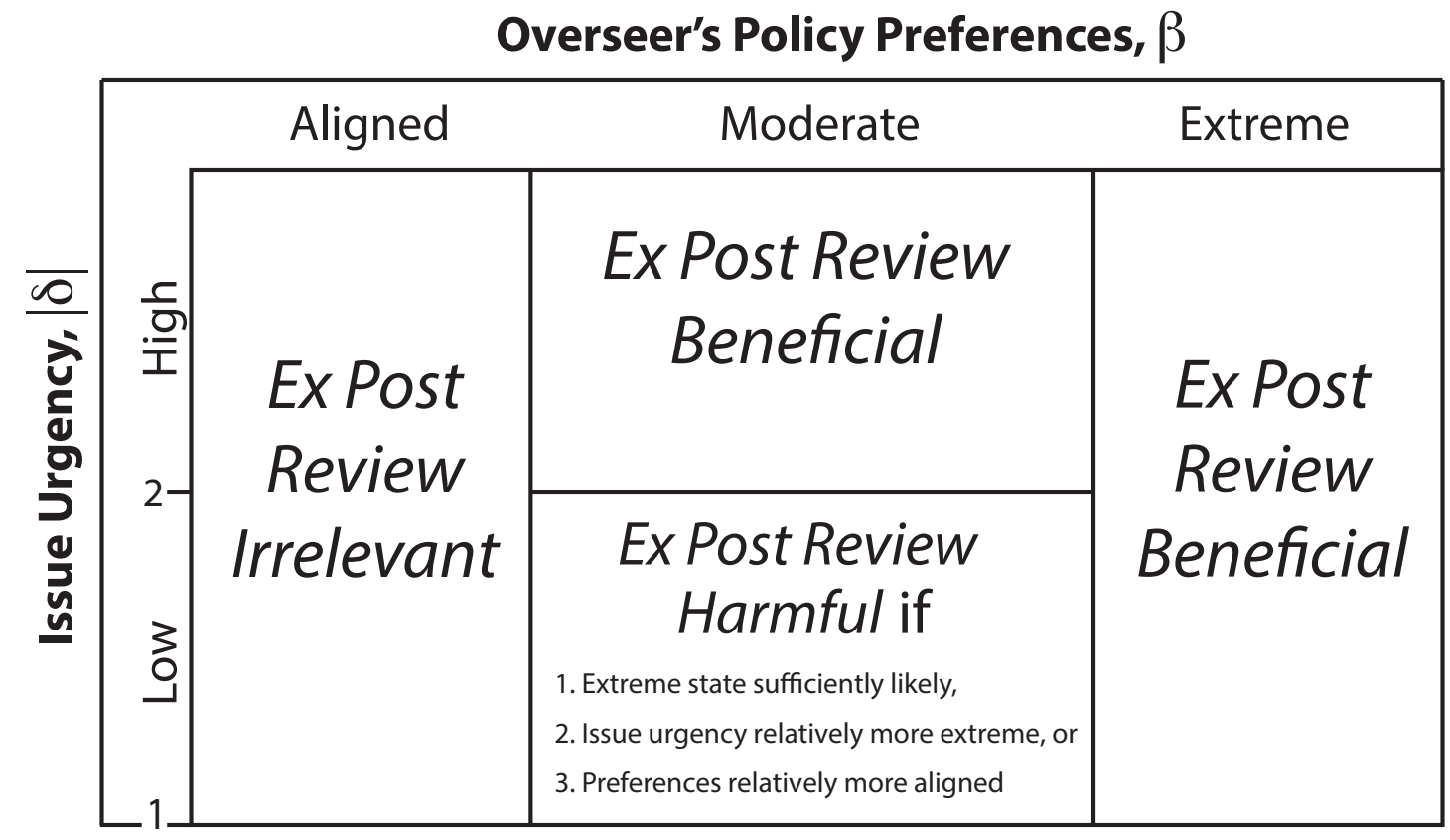

Figure 2: Overseer's Induced Preferences over Ex Post Review

Note: The vertical axis of the figure denotes the absolute level of issue urgency for the extreme state, $|\delta|$. Low urgency issues are $|\delta| \epsilon(1,2]$ and high urgency issues are $|\delta|>2$. The horizontal axis denotes overseer bias. Ex post review is harmful only in the region of low urgency issues and moderate overseer bias as defined in Table 1. If inequality (1) is satisfied then review is always harmful in this region and if inequality (1) is not satisfied then the likelihood review is harmful is increasing as the probability the extreme state $\delta$ obtains increases, as $|\delta|$ increases, and as $\beta$ decreases.

in such situations. In the environment of Proposition 3 the probability of the extreme state is highly likely relative to the moderate state and the agent always cries wolf when the moderate state obtains, which unambiguously harms overseer welfare. In the environment of Proposition 4 the agent does not always cry wolf, but does so with positive probability. That probability is increasing in the likelihood that the extreme state obtains and decreasing in the likelihood that the moderate state obtains. Similarly, as discussed above, ex post review is more likely to harm the overseer when issue urgency, among low urgency issues, increases. That is, ex post review is more likely to be set aside as $|\delta| \rightarrow 2$ than when $|\delta|$ is closer to 1 . Finally, as $\beta \rightarrow 1 / 2$ ex post review is more likely to be harmful, while as $\beta \rightarrow-\delta / 2$ it is less likely to be set aside.

The qualitative thrust of setting aside review also provides some implications for presidential appointments when the overseer is taken to represent the OIRA. Independent regulatory agencies - such as the CFPB and the NLRB - are not formally subject to OIRA review while executive agencies - such as the EPA and the OSHA - are required to submit proposed regulations for OIRA 
review. Due to this distinction, presidential appointment strategies may vary depending on whether that appointment is for an independent or executive agency. Specifically, presidents may place more emphasis on appointing like-minded allies to head up independent agencies, which are formally shielded from OIRA oversight, based on the oversight dynamics described above. The relative exposure of different agencies to different types of oversight suggests that presidential management strategies may vary across independent versus executive agencies.

Having considered the overseer's equilibrium expected benefits and costs from ex post review, we now turn to briefly consider a different institutional design angle: allowing the overseer to "remand" agent decisions, or a two-stage review process.

\subsection{Remanding and Demanding Further Explanation}

Throughout the article we have assumed that the overseer must decide once and for all whether to approve the agent's choice upon first being presented with it. In the real world, of course, the overseer might "send the decision back" to the agent and ask that it be reconsidered, justified, or altered. For example, when federal courts disapprove of a decision of a government agency, they often "remand" the decision to the agency for further review, explanation, and/or refinement. ${ }^{29}$

In section A.3 of the online appendix we formally analyze this process in environments where the agent cries wolf (i.e., moderate preferences and low urgency issues). This allows us to apply our model's insights to see why such 'extended review' institutions might emerge and be sustained. We model the provision of further justification in a simple fashion: when the overseer remands the agent can either demur and accept no policy change or justify his policy choice for a cost. In this setting, provided that justification is neither too cheap nor too costly for the agent, the overseer can deter the agent from crying wolf $\left(x_{A}(-1)=\delta\right)$ and induce the agent to appease her $\left(x_{A}(-1)=0\right)$ by remanding $x_{A}=\delta$.

If the overseer has moderate preferences, she will always remand upon observing $x_{A}=\delta$ and foreseeing this, if justification costs are high enough, the agent will strictly prefer choosing $x_{A}(-1)=$ 0 . Moreover, if justification is not too costly, then the agent will still prefer choosing $x_{A}(\delta)=\delta$.

\footnotetext{
${ }^{29}$ This is the typical course when a court engages in what is known as "substantial evidence review" (for a related model and discussion, see Gailmard and Patty (2017)). This is also analogous to executive review of agency decisionmaking conducted by the Office of Information and Regulatory Affairs.
} 
Rather than cry wolf, the agent now prefers to appease the overseer and behaves analogously to the environment in Proposition 2, which is also a situation in which ex post review is beneficial for the overseer. Thus, if justification is 'moderately costly,' then the ability to remand will restore the overseer's preference for review when she has moderate preferences and issues are low urgency.

This is akin to the overseer requiring a financial regulatory agency to further justify extreme market intervention, perhaps by providing research on market fundamentals pointing to the need for such an intervention. If being able to make the case convincingly is too costly when market indicators call for more moderate intervention then the regulatory agency will instead appease the overseer by foregoing regulation. In that sense, the overseer can induce the agency to take its preferred course of action - no market intervention - and allow for market self-correction due to the increased power it derives from the possibility of remanding and demanding justification.

That the overseer will find review more appealing when given this power is not surprising: this is an unambiguously more flexible version of oversight. Furthermore, if the overseer has the ability to choose the cost of justification then the overseer can always induce the agent to behave desirably. This further implies there is always a justification cost the overseer could choose such that she always prefers retaining review with the possibility of remanding and demanding further justification.

However, allowing remands in this setting increases the overseer's welfare only because we have assumed that remanding (and hence delaying) policy is not in and of itself costly to the overseer. One can imagine environments in which this assumption may not be feasible. Costs for the overseer to remand could represent, for example, OIRA efforts to identify and define sets of requirements that agencies must meet to justify a policy choice. Alternatively, some policy areas in which an extended review process harms public welfare by delaying implementation of a policy could also lead to the overseer internalizing costs for remanding. When remanding is costly to the overseer, the equilibrium discussed above can no longer be supported. This follows from the fact that when remanding successfully induces the agent to choose $x_{A}(-1)=0$ in equilibrium, the overseer must infer that $\theta=\delta$ when $x_{A}=\delta$. Thus, remands are not be credible if they are costly to the overseer.

A full characterization of the mixed strategy, semi-pooling equilibrium that would emerge in this model when remanding is costly, per se, to the overseer is beyond the scope of this article. 
However, such an equilibrium would have an appealing property: the agent would probabilistically choose $x_{A}=\delta$ or $x_{A}=0$ when $\theta=-1$, the overseer would probabilistically remand the agent upon observing $x_{A}=\delta$, and the agent would demur when remanded if and only if $\theta=-1 .{ }^{30}$ Noting that the qualitative features of such decision-making mimics the patterns observed by Wagner (2012) in the judicial review of EPA clean air decisions, we leave this topic for fuller treatment in the future.

\section{Empirical Predictions: Policy Change and Reversals}

Our theory offers empirical predictions about the frequency and nature of both policy changes and reversals. The predictions depend upon both the nature of preferences (aligned, moderate, or extreme) and, in the moderate preference case, on the nature of the issue area (low urgency or high urgency). In this section, we deal with each of these cases in the context of bureaucratic politics. We will at times refer to a bureaucratic agency (rather than 'agent') and a reviewing court (rather than 'overseer') to focus on a particular substantive environment: bureaucratic policymaking in the shadow of judicial review. While the insights apply to many other political oversight situations, focusing on a ubiquitous environment like bureaucratic-judicial relations adds to the substantive intuition underlying the empirical implications. We now turn to analysis of each case.

Aligned Preferences. If the overseer has aligned preferences, there will be policy change, but no reversals. Empirically, then, the theory is consistent with intuition in this case: if one thinks that the overseer and agent have similar preferences, then the agent will exercise significant discretion in practice and the overseer will defer to this behavior. For example, in the context of judicial review of government agencies' decisions, the theory is consonant with the fact that most agency decisionseven conditional upon being challenged in court—are left undisturbed (Eskridge and Baer, 2007). Judicial deference is the norm and we submit that analogous norms of deference prevail in many, if not most, hierarchical policymaking processes. Accordingly, while many theories are consistent with such a regularity, it is nonetheless relevant that our theory is also consistent with it. ${ }^{31}$

\footnotetext{
${ }^{30}$ Whether this equilibrium would improve the overseer's welfare relative to the analogous equilibrium (Propositions 3 and 4) would depend upon various factors, including the overseer's direct cost of remanding the agent's decision.

${ }^{31}$ Of course, styles of review vary across institutions. For example, OIRA is relatively more concerned with the substance of policy and agency justifications of regulatory efficiency (e.g., cost-benefit) and courts may be more concerned with procedural issues. The key insight we provide holds for these situations in the sense that the necessary condition is sufficient disagreement between the agent and overseer. For more detailed formal analysis of OIRA review see, for
} 
Extreme Preferences. If the overseer has extreme preferences, there will be no policy change and no reversals. If behavior were perfectly described by our theory, then this parameter region would not appear in a typical empirical analysis of agency decision-making. If one collected, say, all of the judicial challenges to policy decisions that changed existing policy, then agencies in this parameter region would be naturally excluded from the data, leading to potentially biased estimates of the effect(s) of the various parameters. ${ }^{32}$

Moderate Preferences. If the overseer has moderate preferences, there are two cases to consider: low urgency and high urgency issues. We consider the high urgency case first.

High Urgency Issues. If the issue is high urgency, then Proposition 2 implies that policy change will occur only in extreme situations and that, on the equilibrium path, there will be no reversals. Arguably harder to ferret out of the data will be the fact that policy change is less common than it "should be" from the agent's perspective. Evidence for this behavior within a bureaucratic agency would include reports within the agency that policy change would be desirable, but that the facts do not warrant a policy change that would survive judicial review, while also observing occasional (significant) policy changes that receive judicial deference.

Low Urgency Issues. If the issue is low urgency, then there are two further sub-cases, depending on the likelihood that significant policy change is called for relative to the likelihood that only moderate policy change is warranted.

- Significant Policy Change Commonly Warranted. Proposition 3 implies that, when significant policy change is relatively frequently called for from the agent's perspective, the agent will recommend significant policy change whenever he believes any policy change is called for. Moderate change will never be recommended by an agency in this region and the agency will always receive judicial deference when it pursues a change in policy.

example, Wiseman (2009), and for procedural judicial review in a similar environment see, for example, Turner (2019).

${ }^{32}$ In terms of bureaucratic politics it may seem curious that an agency of this sort would even exist. If the agency never changes policy then why would such an agency be created or maintained? First, even maintenance of the status quo $\left(x_{A}=0\right)$ requires agency action. Second, agencies are often tasked with doing many things across several policy areas and may be more or less aligned with applicable overseers on any given dimension, which implies that perhaps in some policy areas a given agency is driven to forego policy change while in another is free to engage in new policy interventions. Finally, it may be that an agency has 'drifted' over time which has led to an environment of extreme preference divergence and/or that the relevant overseer was replaced or changed her position so that there is now extreme misalignment (e.g., new judicial appointment(s) or Supreme Court directives on an issue, new head of the OIRA, etc.). 
- Significant Policy Change Rarely Warranted. If significant policy change is infrequently called for (relative to moderate policy change), then Proposition 4 implies that when the state calls for moderate policy change the agent will sometimes cry wolf by pursuing extreme changes and other times will forego changing policy at all. Moderate changes to policy will never be observed, and in turn there is positive probability (but not certainty) that the agent will be reversed when he changes policy. Empirically, this implies that agencies will sometimes receive judicial deference following extreme policy changes, while other times similarly extreme policy changes will be met with reversal.

The most interesting case for empirical testing is when the overseer has moderate preferences and significant policy change is rarely warranted because the agent's and overseer's behaviors vary with the parameters of the policymaking process. As an empirical matter, a government agency's decision will be reviewed by a court only if a litigant challenges the decision. In this setting, our theory generates several predictions, the details of which are presented in online appendix A.4.

The Effect of the Overseer's Preferences, $\boldsymbol{\beta}$. The first prediction describes how the agent's behavior and judicial challenges will vary with the alignment of the agent's and overseer's preferences.

Prediction 1 If reversals occur with positive probability, then the agent will choose the extreme policy and face challenge less frequently when the overseer's preferences become more extreme (i.e. for larger values of $\beta$ ). However, the conditional probability that the agent is reversed will be independent of the overseer's preferences.

Prediction 1 implies that as the extremity of a court's preferences increase relative to an agency, the agency will be induced to pursue policy changes that will get it dragged into court less often, but once it is in front of the court the probability it ends up having its policy reversed remains unchanged.

The Effect of the Agent's Aversion to Reversal, $k$. As the agent becomes less averse to reversal ( $k$ decreases), the probability of being reversed increases. However, the frequency of being challenged in court will remain unchanged as this cost varies.

Prediction 2 If reversals occur with positive probability, then agents that find reversal less punitive 
( $k$ closer to zero) will be reversed more often. However, the frequency with which the agent is challenged will be independent of $k$.

If one supposes that the cost of reversal is inversely proportional to the degree that an agency is politically insulated, Prediction 2 implies that more insulated agencies will be overturned more often, but will be no more likely to be subjected to judicial review than less insulated agencies. ${ }^{33}$

The Effect of the Urgency of the Policy Area, $\delta$. When the policy area is more urgent ( $\delta$ larger in absolute value) both the agent and the overseer incur a larger expected cost from reversal and obfuscation in equilibrium. ${ }^{34}$ Accordingly, in equilibrium, the probability the agency is reversed decreases as the urgency of the policy area increases.

Prediction 3 If reversals occur with positive probability then, conditional on proposing a policy change (i.e., $\left.x_{A} \neq 0\right)$, agents will be reversed more often on lower urgency issues ( $\delta$ closer to -1$)$.

Prediction 3 suggests that, conditional upon reviewing an agent's decision, the overseer will appear to be more deferential both to decisions regarding policies with greater uncertainty and to more extreme policy changes.

When the agent is crying wolf with positive probability, the overseer's expected cost of reversal is increasing in issue urgency. This implies that the agent will cry wolf more frequently (and hence be challenged more often) when the issue urgency is higher.

Prediction 4 If reversals occur with positive probability, then the probability that the agent proposes a policy change (i.e., $x_{A} \neq 0$ ) is higher for higher urgency issues ( $\delta$ closer to $\left.-2 \beta\right)$.

Prediction 4 implies that more significant policy changes will be reviewed/challenged more frequently. Putting Predictions 3 and 4 together suggests that the effect of $\delta$ on the ex ante probability

\footnotetext{
${ }^{33}$ In terms of bureaucracy, to the degree that the cost of reversal is inversely correlated with agency-specific features such as independence or insulation, Prediction 2 is also consistent with a model in which these resources are endogenously procured/developed in expectation of agency reversal.

${ }^{34}$ These two effects are actually separate: the cost from reversal is a function of the underlying state $\theta=\delta$ becoming more extreme, implying that reversal of the agent's policy in that state results in both players bearing a larger policy cost. The cost from obfuscation increases because the policy that the agent chooses to avoid reversal when $\theta=-1$ is more extreme. The fact that these effects are aligned is an artifact of the "additive shock" model of policymaking. See Callander (2008, 2011) and Hirsch and Shotts (2012) for models that consider more general specifications of policymaking.
} 
of reversal will be ambiguous. Predictions 3 and 4, and the potential non-montonicity of the ex ante probability of reversal with respect to $\delta$, are illustrated visually in Figure 3.

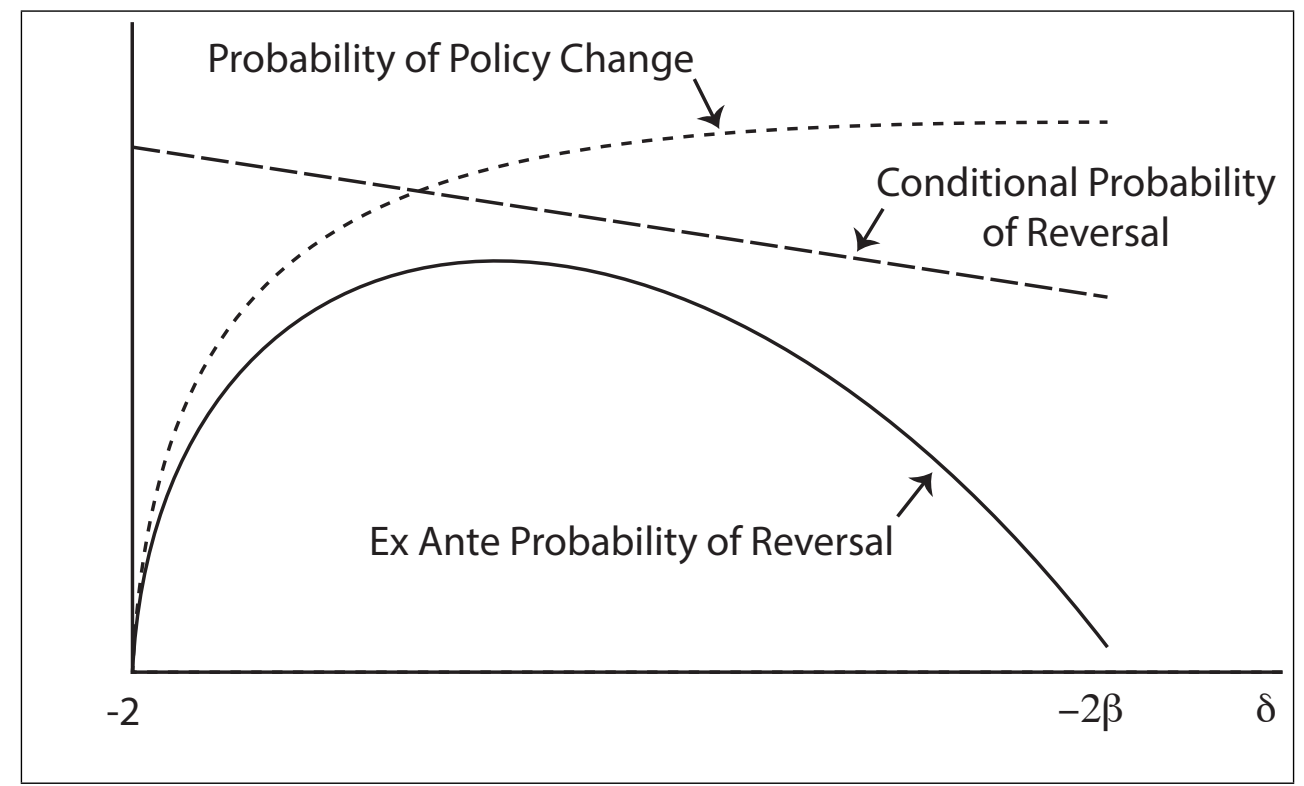

Figure 3: The Effects of Issue Urgency on Frequencies of Policy Change \& Reversal

The point to be drawn from Figure 3 and Predictions 3 and 4 is that the relationship between the importance/urgency of an agent's policy decision can be complicated. The reason for this is that, when the overseer believes that the agent might be obfuscating with an extreme policy proposal (i.e., crying wolf), the extremity of the proposal has two effects on the overseer's incentives. On one hand, the overseer gains more from reversing the agent's decision when the agent is crying wolf but, on the other hand, she pays a larger cost for reversing when the agent is not crying wolf.

\section{Conclusions}

We have presented a theory of how ex post review by an overseer can affect the incentives of her agent charged with making policy decisions. Our theory indicates that the agent's expertise might not be fully expressed in her decision-making when the overseer's policy preferences diverge from the agent's. When this divergence is extreme, the agent has an incentive to never use his or her policy-relevant information. In those cases, the delegation of authority to the agent was superfluous, but the overseer benefits from the neutralizing effect of ex post review. When preference divergence is moderate, there are situations in which the overseer would benefit if she could commit to never engaging in ex post review. This benefit emerges when the agent sometimes attempts to subvert 
the overseer's review by "crying wolf" and choosing a policy that is more extreme than is actually warranted. A simple extension of our theory also indicates that, setting aside the direct costs of imposing a lengthier review process, the overseer would benefit from implementing a two-tiered "remand for further explanation" style oversight system.

In addition to identifying the institutional design incentives of the overseer, our theory also offers predictions regarding the dynamics of policy recommendations in hierarchical systems with ex post review. For example, the theory indicates that reversals will occur only if the agent is actually "crying wolf" with some probability. Furthermore, if reversals occur in equilibrium, their frequency will be a decreasing function of the divergence between the overseer's and agent's preferences. Thus, the theory predicts that, conditional on conflict occurring, it will occur more frequently when the overseer and agent disagree less about policy and that such an increase will emerge solely through the agent attempting to cry wolf more frequently.

The theory also speaks to the probability of reversal conditional upon the agent proposing policy change. Conditional upon proposing a policy change, the probability that the overseer defers to the recommendation decreases as the agent's aversion to reversal increases. Thus, agents who are better insulated or resilient in the face of reversal will be reversed more often. This conditional probability of reversal decreases as the urgency of the issue increases. That is, when the importance of changing policy in the most important situations increases, the overseer will be more deferential. At the same time, as this urgency increases, the agent cries wolf with increasingly high frequency.

While our theory excludes much of reality (as any useful theory necessarily must), we argue that it captures some key features of policymaking, expertise, and deference. Specifically, the theory suggests that behavior and institutional design incentives are sensitive to the preference alignment of both actors and the importance of, and uncertainty inherent to, the policy area in multiple ways, some expected and some less obvious. The key contribution of the theory is to qualitatively characterize the types of situations in which ex post review creates incentives for policy-motivated and reversal-averse (or, perhaps, "career motivated") agents to make pathological policy choices, ironically leading to the possibility that ex post review actually reduces the accountability of the agent. 


\section{References}

Ashworth, Scott. 2012. "Electoral Accountability: Recent Theoretical and Empirical Work.” Annual Review of Political Science 15: 183-201.

Bawn, Kathleen. 1995. "Political Control Versus Expertise: Congressional Choices about Administrative Procedures." American Political Science Review 89(1): 62-73.

Beim, Deborah, Alexander V Hirsch and Jonathan P Kastellec. 2014. "Whistleblowing and Compliance in the Judicial Hierarchy." American Journal of Political Science 58(4): 904-918.

Bendor, Jonathan and Adam Meirowitz. 2004. "Spatial Models of Delegation.” American Political Science Review 98(2): 293-310.

Bueno de Mesquita, Ethan and Matthew C. Stephenson. 2007. "Regulatory Quality under Imperfect Oversight." American Political Science Review 101(3): 605-620.

Callander, Steven. 2008. “A Theory of Policy Expertise.” Quarterly Journal of Political Science 3(2): 123-140.

Callander, Steven. 2011. "Searching for Good Policies.” American Political Science Review 105(4): 643-662.

Callander, Steven and Tom S Clark. 2017. "Precedent and Doctrine in a Complicated World." American Political Science Review 111(1): 184-203.

Cameron, Charles M. 2000. Veto Bargaining: Presidents and the Politics of Negative Power. New York, NY: Cambridge University Press.

Canes-Wrone, Brandice, Michael C. Herron and Kenneth W. Shotts. 2001. "Leadership and Pandering: A Theory of Executive Policymaking." American Journal of Political Science 45(3): 532550. 
Cass, Ronald A. 1989. Review, Enforcement, and Power under the Communications Act of 1934: Choice and Chance in Institutional Design. In A Legislative History of the Communications Act of 1934, ed. Max D. Paglin. New York, NY: Oxford University Press.

Clark, Tom S. 2016. “Scope and Precedent: Judicial Rule-making Under Uncertainty.” Journal of Theoretical Politics 28(3): 353-384.

Clinton, Joshua D, David E Lewis and Jennifer L Selin. 2014. "Influencing the Bureaucracy: The Irony of Congressional Oversight.” American Journal of Political Science 58(2): 387-401.

Crombez, Christophe, Tim Groseclose and Keith Krehbiel. 2006. “Gatekeeping.” Journal of Politics 68(2): 322-334.

Epstein, David and Sharyn O’Halloran. 1994. “Administrative Procedures, Information, and Agency Discretion: Slack vs. Flexibility.” American Journal of Political Science 38(3): 697-722.

Epstein, David and Sharyn O’Halloran. 1995. “A Theory of Strategic Oversight: Congress, Lobbyists, and the Bureaucracy." Journal of Law, Economics, and Organization 11(2): 227-255.

Epstein, David and Sharyn O’Halloran. 1999. Delegating Powers: A Transaction Cost Politics Approach to Policy Making Under Separate Powers. New York, NY: Cambridge University Press.

Eskridge, William N and Lauren E Baer. 2007. “The Continuum of Deference: Supreme Court Treatment of Agency Statutory Interpretations from Chevron to Hamdan.” Georgetown Law Journal 96(4): 1083-1226.

Fox, Justin and Matthew C Stephenson. 2011. "Judicial Review as a Response to Political Posturing." American Political Science Review 105(2): 397-414.

Fox, Justin and Matthew C Stephenson. 2015. "The Welfare Effects of Minority-Protective Judicial Review." Journal of Theoretical Politics 27(4): 499-521.

Fox, Justin and Richard Van Weelden. 2012. "Costly Transparency.” Journal of Public Economics 96(1): 142-150. 
Fox, Justin and Richard Van Weelden. 2015. "Hoping for the Best, Unprepared for the Worst." Journal of Public Economics 130: 59-65.

Gailmard, Sean. 2009. "Oversight and Agency Problems in Legislative-Bureaucratic Interaction." Journal of Theoretical Politics 121(2): 161-186.

Gailmard, Sean and John W. Patty. 2012a. "Formal Models of Bureaucracy." Annual Review of Political Science 15: 353-377.

Gailmard, Sean and John W. Patty. 2012b. Learning While Governing: Information, Accountability, and Executive Branch Institutions. Chicago, IL: University of Chicago Press.

Gailmard, Sean and John W. Patty. 2017. "Participation, Process, \& Policy: The Informational Value of Politicized Judicial Review.” Journal of Public Policy 37(3): 233-260.

Gersen, Jacob E. and Matthew C. Stephenson. 2014. “Over-Accountability.” Journal of Legal Analysis 6(2): 185-243.

Groseclose, Tim and Nolan McCarty. 2001. "The Politics of Blame: Bargaining before an Audience." American Journal of Political Science 45(1): 100-119.

Hammond, Emily. 2011. "Super Deference, the Science Obsession, and Judicial Review as Translation of Agency Science." Michigan Law Review 109: 733.

Hirsch, Alexander V. and Kenneth W. Shotts. 2012. "Policy Specific Information and Informal Agenda Power.” American Journal of Political Science 56(1): 67-83.

Huber, John D. and Charles R. Shipan. 2002. Deliberate Discretion? The Institutional Foundations of Bureaucratic Autonomy. New York, NY: Cambridge University Press.

Jaffe, Louis L. 1965. Judicial Control of Administrative Action. Boston, MA: Little, Brown \& Co. McCann, Pamela J, Charles R Shipan and Yuhua Wang. 2016. "Congress and Judicial Review of Agency Actions.” Working Paper, University of Michigan.

URL: $h t t p: / / g o o . g l / E X u I G U$ 
McCubbins, Mathew, Roger Noll and Barry Weingast. 1987. “Administrative Procedures as Instruments of Political Control." Journal of Law, Economics, and Organization 3(2): 243-277.

McCubbins, Mathew, Roger Noll and Barry Weingast. 1989. "Structure and Process, Politics and Policy: Administrative Arrangements and the Political Control of Agencies." Virginia Law Review 75(2): 431-489.

McCubbins, Mathew and Tom Schwartz. 1984. "Congressional Oversight Overlooked: Police Patrols versus Fire Alarms.” American Journal of Political Science 28(1): 165-179.

Meazell, Emily Hammond. 2011. "Deference and Dialogue in Administrative Law." Columbia Law Review 111(8): 1722-1787.

Melnick, R. Shep. 1983. Regulation and the Courts: The Case of the Clean Air Act. Washington, DC: The Brookings Institution Press.

Miller, Gary J. 2005. “The Political Evolution of Principal-Agent Models.” Annual Review of Political Science 8: 203-225.

Romer, Thomas and Howard Rosenthal. 1978. "Political Resource Allocation, Controlled Agendas, and the Status Quo.” Public Choice 33: 27-43.

Rose-Ackerman, Susan. 1995. Controlling Environmental Policy. New Haven, CT: Yale University Press.

Shapiro, Sidney A. and Richard E. Levy. 1995. "Judicial Incentives and Indeterminacy in Substantive Review of Administrative Decisions." Duke Law Journal 44(6): 1051-1080.

Shipan, Charles. 1997. Designing Judicial Review. Ann Arbor, MI: University of Michigan Press.

Shipan, Charles R. 2000. “The Legislative Design of Judicial Review: A Formal Analysis.” Journal of Theoretical Politics 12(3): 269-304.

Smith, Joseph L. 2005. "Congress Opens the Courthouse Doors: Statutory Changes to Judicial Review Under the Clean Air Act.” Political Research Quarterly 58(1): 139-149. 
Smith, Joseph L. 2006. “Judicial Procedures as Instruments of Political Control: Congress’s Strategic Use of Citizen Suits.” Legislative Studies Quarterly 31(2): 283-305.

Turner, Ian R. 2017. "Working Smart and Hard? Agency Effort, Judicial Review, and Policy Precision." Journal of Theoretical Politics 29(1): 69-96.

Turner, Ian R. 2019. "Reviewing Procedure vs. Judging Substance: The Scope of Review and Bureaucratic Policymaking." Unpublished Manuscript. Yale University.

URL: https://ssrn.com/abstract=3019371

Turner, Ian R. Forthcoming. "Political Agency, Oversight, and Bias: The Instrumental Value of Politicized Policymaking." Journal of Law, Economics, \& Organization.

Vanberg, Georg. 2001. "Legislative-Judicial Relations: A Game-Theoretic Approach to Constitutional Review." American Journal of Political Science 45(2): 346-361.

Wagner, Wendy. 2012. "Revisiting the Impact of Judicial Review on Agency Rulemakings: An Empirical Investigation.” William \& Mary Law Review 53(5): 1717-1795.

Wiseman, Alan E. 2009. "Delegation and Positive-Sum Bureaucracies." The Journal of Politics 71(03): 998-1014.

Zaring, David. 2010. “Reasonable Agencies.” Virginia Law Review 96(1): 135-197. 


\section{A Online Supplemental Appendix}

\section{A.1 Derivation of Best Response to Truthful Policymaking}

To investigate best responses for the overseer given truthful policymaking there are three cases: $x_{A}=\theta=0 ; x_{A}=\theta=-1 ; x_{A}=\theta=\delta$. We consider each in turn; first considering the overseer's payoff for upholding the agent relative to overturning the agent.

Case 1. $x_{A}=\theta=0$. Consider the overseer's payoff for upholding a truthful agent following $x_{A}=0$,

$$
\begin{aligned}
U_{R}\left(r=0 \mid x_{A}=\theta=0\right) & =-(\theta+\beta-(1-r) x)^{2}, \\
& =-\beta^{2} .
\end{aligned}
$$

Now consider the overseer's payoff for reversing the agent following $x_{A}=0$,

$$
\begin{aligned}
U_{R}\left(r=1 \mid x_{A}=\theta=0\right) & =-(\theta+\beta-(1-r) x)^{2}, \\
& =-\beta^{2} .
\end{aligned}
$$

Thus, in a truthful equilibrium following $x_{A}=0$ the overseer is indifferent between upholding or reversing the agent. For simplicity, we suppose that the overseer breaks her indifference by upholding. So, when $x_{A}=0$ and the agent is setting policy truthfully the overseer upholds the agent (this, obviously, holds for any value of $\beta \geq 0$ ).

Case 2. $x_{A}=\theta=-1$. Now consider the overseer's payoff from upholding a truthful agent when $x_{A}=-1$,

$$
\begin{aligned}
U_{R}\left(r=0 \mid x_{A}=\theta=-1\right) & =-(\theta+\beta-(1-r) x)^{2}, \\
& =-\beta^{2} .
\end{aligned}
$$


Now consider the overseer's payoff from reversing a truthful agent following $x_{A}=-1$,

$$
\begin{aligned}
U_{R}\left(r=1 \mid x_{A}=\theta=-1\right) & =-(\theta+\beta-(1-r) x)^{2}, \\
& =-(\beta-1)^{2} .
\end{aligned}
$$

In this case the overseer will reverse the agent if and only if $U_{P}\left(r=1 \mid x_{A}=\theta=-1\right)>U_{P}\left(r=0 \mid x_{A}=\right.$ $\theta=-1$ ) (and of course will uphold if the reverse is true). So, the overseer will reverse the agent whenever:

$$
\begin{gathered}
U_{R}\left(r=1 \mid x_{A}=\theta=-1\right)>U_{P}\left(r=0 \mid x_{A}=\theta=-1\right), \\
\beta>1 / 2 .
\end{gathered}
$$

Thus, the overseer will uphold a faithful agent following $x_{A}=-1$ if and only if $\beta \leq 1 / 2$, and will reverse the agent following $x_{A}=-1$ if $\beta>1 / 2$.

Case 3. $x_{A}=\theta=\delta$. Finally, consider the overseer's payoff for upholding a truthful agent following $x_{A}=\delta$,

$$
\begin{aligned}
U_{R}\left(r=0 \mid x_{A}=\theta=\delta\right) & =-(\theta+\beta-(1-r) x)^{2}, \\
& =-\beta^{2} .
\end{aligned}
$$

Now consider the overseer's payoff for reversing a truthful agent following $x_{A}=\delta$,

$$
\begin{aligned}
U_{R}\left(r=1 \mid x_{A}=\theta=\delta\right) & =-(\theta+\beta-(1-r) x)^{2}, \\
& =-(\delta+\beta)^{2} .
\end{aligned}
$$


In this case the overseer will reverse the agent if and only if $U_{R}\left(r=1 \mid x_{A}=\theta=\delta\right)>U_{R}\left(r=0 \mid x_{A}=\right.$ $\theta=\delta)$. So the overseer will reverse the agent if,

$$
\begin{gathered}
U_{R}\left(r=1 \mid x_{A}=\theta=\delta\right)>U_{R}\left(r=0 \mid x_{A}=\theta=\delta\right), \\
\beta>-\frac{\delta}{2} .
\end{gathered}
$$

Thus, the overseer will uphold the agent, given truthful policymaking, following $x_{A}=\delta$ if and only if $\beta \leq-\frac{\delta}{2}>1 / 2$. If $\beta>-\frac{\delta}{2}$, the overseer will reverse the agent following $x_{A}=\delta$.

Taking these three cases together yields the best response function as displayed in Table 1.

\section{A.2 Proofs of In-text Results}

Proposition 1 If the reversal cost is positive $(k>0)$, then there is a truthful separating equilibrium in which the agent always matches policy to the state $\left(s_{A}^{*}(\theta)=\theta\right)$ if and only if the overseer has aligned preferences (i.e., $\beta \leq 1 / 2$ ). Moreover, if the principal has extreme preferences (i.e., $\beta>-\frac{\delta}{2}$ ) then, in any equilibrium, the agent chooses $x_{A}=0$ for all values of $\theta$.

Proof: We first prove the result that, given $k>0$, there is a truthful separating equilibrium if and only if the overseer has aligned preferences.

Sufficiency. If $\beta \leq 1 / 2$, the overseer always weakly prefers $x_{A}=\theta$ to $x_{A}=0$ and so will not reverse a truthful agent. The agent always prefers $x_{A}=\theta$ if $x_{A}=\theta$ will not be reversed.

Necessity. For the purpose of obtaining a contradiction, suppose that $s^{*}=\left(s_{A}^{*}, s_{R}^{*}\right)$ is an equilibrium and that $s_{A}^{*}=s_{A}^{\text {truthful }}(\theta)=\theta$. Then, the overseer must infer that $\theta=-1$ when $x_{A}=-1$, so that, if $s_{R}^{*}$ is sequentially rational, the fact that $\beta>1 / 2$ implies that $s_{R}^{*}(-1)=1$. The agent can strictly increase his or her expected payoff by choosing $x_{A}=0$ conditional on observing $\theta=-1$, contradicting the supposition that $s^{*}$ is an equilibrium.

Next, we prove the result that when the principal has extreme preferences the agent always sets $x_{A}=0$. For the overseer, $r=1$ is a strictly dominant action whenever $x_{A} \neq 0$. Iterated elimination of dominated strategies yields $s_{A}^{*}(\theta)=0$ as the iteratively dominant strategy for the agent.

Proposition 2 If the overseer has moderate preferences $\left(\beta \in\left(\frac{1}{2},-\frac{\delta}{2}\right]\right)$, and $\delta<-2$, then, there is an 
equilibrium $s^{*}=\left(s_{A}^{*}, s_{R}^{*}\right)$, in which the agent chooses $x_{A}=0$ whenever $\theta \in\{-1,0\}$ :

$$
s_{A}^{*}(0)=s_{A}^{*}(-1)=0,
$$

chooses $x_{A}=\delta$ when $\theta=\delta$ :

$$
s_{A}^{*}(\delta)=\delta,
$$

and the overseer upholds $x_{A} \in\{\delta, 0\}$ and reverses $x_{A}=-1$ :

$$
s_{R}^{*}(x)= \begin{cases}1 & \text { if } x_{A}=-1, \\ 0 & \text { if } x_{A} \in\{0, \delta\} .\end{cases}
$$

Proof: If the agent employs $s_{A}^{*}$ and the overseer's beliefs are consistent with this strategy, the overseer will uphold the agent upon observing $x_{A}=\delta$ because $\beta \in\left(\frac{1}{2},-\frac{\delta}{2}\right]$. Similarly, the overseer will uphold the agent upon observing $x_{A}=0$ because she is indifferent about reversing this policy. To complete the sequential rationality of $s_{R}^{\star}$, define the overseer's off-the-equilibrium-path beliefs upon observing $x_{A}=-1$ as $\operatorname{Pr}[\theta=-1 \mid x=-1]=1$ (i.e., presuming "sincerity" by the agent).

To check that $s_{A}^{*}$ is a best response to $s_{R}^{*}$, note it is necessary only to consider $s_{A}^{*}(-1)$. Proposing $x_{A}=-1$ will result in a strictly lower payoff than proposing $s_{A}^{*}(-1)=0$ (i.e., $-(1+k)$ versus -1 ). Proposing $x_{A}=\delta$ will also result in a lower payoff by the assumption that $\delta<-2$ (i.e., $\left.-(\delta+1)^{2}<-1\right)$. The agent is clearly best responding under $s_{A}^{*}$ when $\theta \in\{0, \delta\}$. Accordingly, $s_{A}^{*}$ is a best response to $s_{R}^{*}$, implying that $\left(s_{A}^{*}, s_{R}^{*}\right)$ (along with appropriate and consistent beliefs by the overseer) is a perfect Bayesian equilibrium, as was to be shown.

Proposition 3 If the issue is low urgency $(\delta \in[-2,-1))$, the overseer has moderate preferences $\left(\beta \in\left(\frac{1}{2},-\frac{\delta}{2}\right]\right)$, and

$$
\frac{p_{-1}}{p_{\delta}+p_{-1}} \leq \frac{\delta+2 \beta}{2(1+\delta)}
$$

then there is an equilibrium in which the agent chooses $x_{A}=\delta$ for both $\theta \in\{\delta,-1\}$ and $x_{A}=0$ for 
$\theta=0$ :

$$
s_{A}^{\text {pure semi-pool }}(\theta)= \begin{cases}0 & \text { if } \theta=0, \\ \delta & \text { if } \theta \in\{-1, \delta\},\end{cases}
$$

and the overseer upholds $x_{A} \in\{\delta, 0\}$ and reverses $x_{A}=-1$ :

$$
s_{R}(x)= \begin{cases}1 & \text { if } x_{A}=-1 \\ 0 & \text { if } x_{A} \in\{0, \delta\} .\end{cases}
$$

Proof: Consider the following "pure" semi-pooling strategy for the agent:

$$
s_{A}^{\text {pure semi-pool }}(\theta)= \begin{cases}0 & \text { if } \theta=0, \\ \delta & \text { if } \theta \in\{-1, \delta\} .\end{cases}
$$

If the agent employs $s_{A}^{\text {pure semi-pool }}$, the overseer will uphold the agent upon observing $x_{A}=\delta$ only if the following inequality holds:

$$
-\left(\frac{p_{-1}}{p_{\delta}+p_{-1}}(\beta-1)^{2}+\frac{p_{\delta}}{p_{\delta}+p_{-1}}(\beta+\delta)^{2}\right) \leq-\left(\frac{p_{-1}}{p_{\delta}+p_{-1}}(\beta-1-\delta)^{2}+\frac{p_{\delta}}{p_{\delta}+p_{-1}} \beta^{2}\right)
$$

or if the following is satisfied:

$$
\frac{p_{-1}}{p_{\delta}+p_{-1}} \leq \frac{\delta+2 \beta}{2(1+\delta)}
$$

Thus, given that the overseer has beliefs consistent with $s_{A}^{\text {pure semi-pool }}, s_{R}$ is a best response to $s_{A}^{\text {pure semi-pool }}$. To see that $s_{A}^{\text {pure semi-pool }}$ is a best response to $s_{R}$, one need consider only the agent's incentives when confronted with $\theta=-1$, because the agent's (state-conditioned) most-preferred policy is being upheld under this profile in the other two states. When $\theta=-1$, the agent prefers $x_{A}=\delta$ to $x_{A}=0$ (each of which would be upheld) because the issue is low urgency $(\delta \in[-2,-1)$ ). Finally, choosing $x_{A}=-1$ results in the agent being reversed and the final policy outcome being set back to $x=0$. Accordingly, $s_{A}^{\text {pure semi-pool }}$ is a best response to $s_{R}$, implying that $\left(s_{A}^{\text {pure semi-pool }}, s_{R}\right)$ (along with 
consistent beliefs by the principal) is a perfect Bayesian equilibrium, as was to be shown.

Proposition 4 If the overseer has moderate preferences $\left(\beta \in\left(\frac{1}{2},-\frac{\delta}{2}\right]\right)$, and inequality (1) does not hold:

$$
\frac{p_{-1}}{p_{\delta}+p_{-1}}>\frac{\delta+2 \beta}{2(1+\delta)}
$$

then there is an equilibrium in which the agent mixes between $x_{A}=\delta$ and $x_{A}=0$ when $\theta=-1$, and chooses $x_{A}=\theta$ for $\theta \in\{0, \delta\}$ :

$$
s_{A}^{\text {mixed semi-pool }}(\theta)= \begin{cases}\delta & \text { with probability } \frac{p_{\delta}(2 \beta+\delta)}{p_{-1}(\delta-2 \beta+2)} \text { if } \theta=-1, \\ 0 & \text { with probability } 1-\frac{p_{\delta}(2 \beta+\delta)}{p_{-1}(\delta-2 \beta+2)} \text { if } \theta=-1, \\ \theta \quad & \text { if } \theta \in\{0, \delta\},\end{cases}
$$

and the overseer reverses $x_{A}$ as follows:

$$
s_{R}(x)= \begin{cases}0 \quad & \text { if } x_{A}=0, \\ 1 & \text { if } x_{A}=-1, \\ 0 \quad & \text { with probability } \frac{k}{-\left(2 \delta+\delta^{2}\right)+k} \text { if } x_{A}=\delta, \\ 1 \quad \text { with probability } \frac{-\left(2 \delta+\delta^{2}\right)}{-\left(2 \delta+\delta^{2}\right)+k} \text { if } x_{A}=\delta .\end{cases}
$$

Proof: Suppose that the overseer has moderate preferences $\left(\beta \in\left(\frac{1}{2},-\frac{\delta}{2}\right]\right)$, and inequality (1) is satisfied. It is simple to show that, given the overseer's strategy, the agent's best response is $x_{A}=0$ when $\theta=0$ and, supposing that the agent is best responding by mixing when $\theta=-1$, that the agent's best response when $\theta=\delta$ is $x_{A}=\delta$. The overseer's response to $x_{A}=0$ is also clearly a best response. Thus, the only questions that remain regard whether the agent is best-responding when $\theta=-1$ and whether the overseer is best-responding when $x_{A}=\delta$. The answers to these two questions boil down to deriving when the two players are indifferent between the two actions prescribed by each of their strategies in those situations. 
If the agent chooses $x_{A}=-1$, his or her payoff is $-(1+k)$. If the agent chooses $x_{A}=0$, his or her payoff is -1 , so the mixing by the agent upon observing $\theta=-1$ would be between $x_{A}=0$ and $x_{A}=\delta$. Letting $\omega \equiv \operatorname{Pr}\left[x_{A}=\delta \mid \theta=-1\right]$ denote the conditional probability that the agent chooses $\delta$ after observing $\theta=-1$, the overseer can mix between $r=0$ and $r=1$ upon observing $x_{A}=\delta$ only if equation (5) is satisfied with equality.

$$
\frac{p_{-1} \omega}{p_{\delta}+p_{-1} \omega}=\frac{\delta+2 \beta}{2(1+\delta)}
$$

which implies that

$$
\omega=\frac{p_{\delta}(2 \beta+\delta)}{p_{-1}(\delta-2 \beta+2)}
$$

Note that (1) $\delta<0$ and $2 \beta<-\delta$, so that $2 \beta+\delta<0$ and (2) $\delta-2 \beta<-2$, so that $\delta-2 \beta+2<0$, implying that $\omega$ as defined in equation (6) is positive. Furthermore, $\omega$ as defined in equation (6) is less than one whenever $\frac{p_{-1}}{p_{\delta}+p_{-1}}>\frac{\delta+2 \beta}{2(1+\delta)}$ (i.e., whenever inequality (1) does not hold).

The agent's expected payoff from choosing $x_{A}=\delta$, letting $\rho \equiv \operatorname{Pr}\left[r=1 \mid x_{A}=\delta\right]$ denote the probability of reversal, is

$$
E U_{A}\left(x_{A}=\delta \mid \theta=-1, \rho\right)=-(1-\delta)^{2}(1-\rho)-\rho(1+k)
$$

and his expected payoff from choosing $x_{A}=0$ in the same situation is

$$
E U_{A}\left(x_{A}=0 \mid \theta=-1, \rho\right)=-1,
$$

so that, in order to choose $\omega \in(0,1)$, it must be the case that

$$
\begin{aligned}
E U_{A}\left(x_{A}=\delta \mid \theta=-1, \rho\right) & =E U_{A}\left(x_{A}=0 \mid \theta=-1, \rho\right), \\
\rho & =\frac{-\left(2 \delta+\delta^{2}\right)}{-\left(2 \delta+\delta^{2}\right)+k},
\end{aligned}
$$

Note that $\delta \in(-2,-1]$ and $k \geq 0$ implies that $\rho \in[0,1]$. If $s_{R}(\delta)=\rho$, then the agent is indifferent between choosing $x_{A}=\delta$ and $x_{A}=0$ when $\theta=-1$, and can choose $x_{A}=\delta$ with probability $\omega$ and 
$x_{A}=0$ with probability $1-\omega$. Doing so and choosing $x_{A}=\theta$ with probability one for $\theta \in\{0, \delta\}$, consistency of the overseer's beliefs implies that the overseer is indifferent between $r=0$ and $r=1$ upon observing $x_{A}=\delta$, so that she can choose $r=1$ with probability $\rho$ and $r=0$ with probability $1-\rho$. To complete the derivation, set the overseer's (off-path) beliefs after observing $x_{A}=-1$ equal to $\operatorname{Pr}\left[\theta=-1 \mid x_{A}=-1\right]=1$.

Proposition 5 From an ex ante welfare perspective, ex post review affects the overseer as follows:

1. When the overseer has aligned preferences ex post review is irrelevant,

2. When the overseer has extreme preferences ex post review is beneficial,

3. When the overseer has moderate preferences ex post review is harmful if and only if extreme states are of low urgency and (i) the agent always cries wolf(i.e., inequality 1 is satisfied) or (ii) the agent cries wolf probabilistically (i.e., inequality 1 is not satisfied) and $\delta p_{\delta}(2 \beta+\delta)+$ $p_{-1}(1-2 \beta) \geq 0$.

Proof: Let $\Delta V_{R}^{\text {Review }} \equiv V_{R}^{\text {Review }}-V_{R}^{\text {No Review }}$ be the overseer's welfare for retaining ex post review. When $\Delta V_{R}^{\text {Review }}>0$ the overseer benefits from ex post review, when $\Delta V_{R}^{\text {Review }}<0$ the overseer benefits from setting aside ex post review (i.e., ex post review is harmful), and when $\Delta V_{R}^{\text {Review }}=0$ ex post review is irrelevant for the overseer's ex ante welfare. We deal with each case listed in the result in turn. Recall first that the overseer's expected payoff from setting aside ex post review is,

$$
V_{R}^{\text {No Review }}=-\beta^{2}
$$

Aligned preferences. Consider the case in which the overseer has aligned preferences so that $\beta \leq \frac{1}{2}$. In this case, per Proposition 1, the agent will always match policy to the state and the overseer will always uphold following truthful policymaking. Thus, the overseer's payoff from retaining ex post review is,

$$
\begin{aligned}
V_{R}^{\text {Review }} & =-\left(p_{0} \beta^{2}-p_{-1} \beta^{2}-p_{\delta} \beta^{2}\right) \\
& =-\beta^{2},
\end{aligned}
$$


which implies that,

$$
\Delta V_{R}^{\text {Review }}=-\beta^{2}+\beta^{2}=0
$$

Thus, when the overseer has aligned preferences ex post review is irrelevant from an ex ante welfare perspective.

Extreme preferences. Next, consider the case in which the overseer has extreme preferences so that $\beta>-\frac{\delta}{2}$. In this case the agent always sets $x_{A}=0$ (per Proposition 1), which implies that retaining ex post review leads to a payoff, conditional on state, of

$$
V_{R}^{\text {Review }}=-\left(p_{0} \beta^{2}+p_{-1}(\beta-1)^{2}+p_{\delta}(\beta+\delta)^{2}\right)
$$

Combining and rearranging we obtain the overseer's net expected payoff from retaining ex post review, $\Delta V_{R}^{\text {Review }} \equiv V_{R}^{\text {Review }}-V_{R}^{\text {No Review }}$

$$
\begin{aligned}
\Delta V_{R}^{\text {Review }} & =\beta^{2}-\left(p_{0} \beta^{2}+p_{-1}(\beta-1)^{2}+p_{\delta}(\beta+\delta)^{2}\right) \\
& =\beta^{2}-\left(p_{0} \beta^{2}+p_{-1} \beta^{2}-2 \beta p_{-1}+p_{-1}+p_{\delta} \beta^{2}+2 \beta \delta p_{\delta}+p_{\delta} \delta^{2}\right), \\
& =\beta^{2}-\beta^{2}-p_{-1}+2 \beta p_{-1}-2 \beta p_{-1}-2 \beta \delta p_{\delta}-p_{\delta} \delta^{2}, \\
& =2 \beta p_{-1}-p_{-1}-2 \beta \delta p_{\delta}-p_{\delta} \delta^{2} \\
& =p_{-1}(2 \beta-1)-p_{\delta}\left(2 \beta \delta-\delta^{2}\right) .
\end{aligned}
$$

Given that $\beta>-\frac{\delta}{2}, \delta \in\left(\frac{1}{2},-\frac{\delta}{2}\right]$, and $p_{-1} \in(0,1), p_{\delta} \in(0,1)$, it follows that $\Delta V_{R}^{\text {Review }}>0$, implying that the overseer benefits from the retention of ex post review when she has extreme preferences.

Moderate preferences. Finally, consider the case in which the overseer has moderate preferences so that $\beta \in\left(\frac{1}{2},-\frac{\delta}{2}\right]$. First, we show that when issue urgency is high ex post review is beneficial (i.e., not harmful) to the overseer's welfare. Then we conclude the proof by deriving the expression that must be satisfied in order for ex post review to be harmful when issue urgency is low.

High urgency. Let $\delta<-2$ so that extreme states are high urgency. In this environment Proposition 2 implies that the agent will obfuscate when $\theta=-1$ by choosing $x_{A}=0$ (rather than crying wolf and 
choosing $x_{A}=\delta$ ). Accordingly, the overseer's welfare from retaining ex post review is given by,

$$
\begin{aligned}
V_{R}^{\text {Review }} & =-\left(p_{0} \beta^{2}-p_{-1}(\beta-1)^{2}+p_{\delta} \beta^{2}\right), \\
& =-\left(-p_{0} \beta^{2}-p_{-1} \beta^{2}-p_{\delta} \beta^{2}+2 \beta p_{-1}-p_{-1}\right), \\
& ==\beta^{2}+2 \beta p_{-1}-p_{-1},
\end{aligned}
$$

further implying that,

$$
\begin{aligned}
\Delta V_{R}^{\text {Review }} & =\beta^{2}-\beta^{2}+2 \beta p_{-1}-p_{-1} \\
& =p_{-1}(2 \beta-1)
\end{aligned}
$$

Note that $\Delta V_{R}^{\text {Review }}=0$ when $\beta=\frac{1}{2}$ and is increasing in $\beta$, implying that $\Delta V_{R}^{\text {Review }}>0$ for all $\beta \in\left(\frac{1}{2},-\frac{\delta}{2}\right]$ given that $\delta<-2$ and $p_{-1} \in(0,1)$. (The inequality also holds weakly for $p_{-1} \in[0,1]$.) This further implies that when the overseer has moderate preferences and extreme states are high urgency the overseer benefits from ex post review, as stated in the result.

Low urgency. When $\delta \in(-2,-1)$ issues are low urgency and agent behavior depends on the relative likelihood that $\theta=\delta$ compared to $\theta=-1$. Specifically, if inequality 1 is satisfied then the agent always cries wolf as in Proposition 3 (i.e., chooses $x_{A}=\delta$ when $\theta \in\{\delta,-1\}$ ) and when inequality 1 is not satisfied the agent mixes as defined in Proposition 4. First, consider the environment of Proposition 3 when inequality 1 is satisfied. In this case the agent chooses $x_{A}(\theta)=\delta$ for $\theta \in\{\delta,-1\}$ and $x_{A}(0)=0$. Accordingly, the overseer's net welfare from retaining ex post review is given by,

$$
\begin{aligned}
\Delta V_{R}^{\text {Review }} & =\beta^{2}-\left(p_{0} \beta^{2}+p_{-1}(\beta-1-\delta)^{2}+p_{\delta} \beta^{2}\right) \\
& =\beta^{2}-\beta^{2}+2 \beta \delta p_{-1}+2 \beta p_{-1}-\delta^{2} p_{-1}-2 \delta p_{-1}-p_{-1} \\
& =2 \beta \delta p_{-1}+2 \beta p_{-1}-\delta^{2} p_{-1}-2 \delta p_{-1}-p_{-1}, \\
& =2 \beta p_{-1}(\delta+1)-p_{-1}\left(\delta^{2}+2 \delta+1\right) .
\end{aligned}
$$

Given the restrictions on $\beta$ and $\delta$, and that $p_{-1} \in(0,1)$, it follows that $\Delta V_{R}^{\text {Review }}<0$, implying that 
the overseer benefits from setting aside ex post review in this environment.

Finally, if the extreme state is sufficiently unlikely (inequality (1) is not satisfied), the overseer's expected payoff from the mixed strategy equilibrium described in Proposition 4 is equal to

$$
\begin{gathered}
V_{R}^{\text {Review }}=-p_{0} \beta^{2}-p_{-1}\left(\omega(1-\rho)(\beta-1-\delta)^{2}+(1-\omega+\omega \rho)(\beta-1)^{2}\right)-p_{\delta}\left((1-\rho) \beta^{2}+\rho(\beta+\delta)^{2}\right), \\
\omega \equiv \operatorname{Pr}[x=\delta \mid \theta=-1]=\frac{p_{\delta}(2 \beta+\delta)}{p_{-1}(\delta-2 \beta+2)} \text { and } \rho \equiv \operatorname{Pr}[r=1 \mid x=\delta]=\frac{-\left(2 \delta+\delta^{2}\right)}{-\left(2 \delta+\delta^{2}\right)+k} \text { (from Proposition 4). }
\end{gathered}
$$

Thus, given $V_{R}^{\text {No Review }}=-\beta^{2}$, setting aside ex post review is beneficial to the overseer only if

$$
\begin{aligned}
-\beta^{2} \geq & -p_{0} \beta^{2}-p_{-1}\left(\omega(1-\rho)(\beta-1-\delta)^{2}+(1-\omega+\omega \rho)(\beta-1)^{2}\right) \\
& -p_{\delta}\left((1-\rho) \beta^{2}+\rho(\beta+\delta)^{2}\right), \\
\beta^{2} \leq & p_{0} \beta^{2}+p_{-1}\left(\omega(1-\rho)(\beta-1-\delta)^{2}+(1-\omega+\omega \rho)(\beta-1)^{2}\right) \\
& +p_{\delta}\left((1-\rho) \beta^{2}+\rho(\beta+\delta)^{2}\right), \\
\left(1-p_{0}-p_{\delta}(1-\rho)\right) \beta^{2} \leq & p_{-1}\left(\omega(1-\rho)(\beta-1-\delta)^{2}+(1-\omega+\omega \rho)(\beta-1)^{2}\right)+p_{\delta} \rho(\beta+\delta)^{2}, \\
0 \leq & p_{-1}\left(\omega(1-\rho)\left(\delta^{2}-2 \beta \delta-2 \delta\right)+1-2 \beta\right)+p_{\delta} \rho\left(2 \beta \delta+\delta^{2}\right), \\
0 \leq & p_{-1}\left(\frac{p_{\delta}(2 \beta+\delta)}{p_{-1}(\delta-2 \beta+2)}(1-\rho)\left(\delta^{2}-2 \beta \delta-2 \delta\right)+1-2 \beta\right)+p_{\delta} \rho\left(2 \beta \delta+\delta^{2}\right), \\
0 \leq & \delta p_{\delta}(2 \beta+\delta)(1-\rho)+p_{-1}(1-2 \beta)+p_{\delta} \rho\left(2 \beta \delta+\delta^{2}\right), \\
0 & \delta p_{\delta}(2 \beta+\delta)+p_{-1}(1-2 \beta) .
\end{aligned}
$$

Thus, $\Delta V_{R}^{\text {No Review }} \equiv V_{R}^{\text {No Review }}-V_{R}^{\text {Review }} \geq 0 \Longleftrightarrow \delta p_{\delta}(2 \beta+\delta)+p_{-1}(1-2 \beta) \geq 0$, as stated in the result.

\section{A.3 Remanding and Demanding Further Justification}

In this section we provide the formal foundations for our discussion in section 3.2 in the main text. Specifically, we analyze how agent policymaking changes when the overseer has the ability to extend the review process by "remanding and demanding further justification" from the agent. We show that when the overseer can costlessly remand the agent she can obtain equilibrium welfare equivalent to the case of moderate preferences and high urgency issues (Proposition 2). That is, 
when the overseer has an additional oversight tool at her disposal, and justification is costly to the agent, the overseer's preference to retain ex post review can be restored. We conclude by showing that any time remanding is at all costly this equilibrium can no longer be supported.

To model justifications we introduce a cost, $J>0$, to capture the extra work that the agent must do to justify his remanded policy choice. We denote this choice by $\gamma\left(x_{A}\right) \in\{0,1\}$, which captures whether he would justify each potential policy choice. Specifically, $\gamma\left(x_{A}\right)=0$ means the agent demurs upon remand and $\gamma\left(x_{A}\right)=1$ means the agent (pays $J$ and) justifies his choice of $x_{A}$. For simplicity we assume that (1) when the agent demurs final policy is the same as in the case the overseer outright overturns: $x=0$ and (2) when the agent justifies his choice the overseer ultimately upholds the policy: $x=x_{A}$. Finally, we assume that the agent still incurs the reputational cost $k>0$ when remanded.

The overseer now has an additional institutional tool at her disposal: the ability to remand and demand further justification, $R \in\{0,1\}$. If $R=1$ then the overseer remands and if $R=0$ she does not. The overall review decision $r \in\{0,1\}$ remains defined the same. However, in the case of a remand the agent ultimately dictates $r$ indirectly through his choice of $\gamma\left(x_{A}\right)$. With these preliminaries in hand we present the key result that shows that when the overseer can remand she can deter the agent from crying wolf by remanding $x_{A}=\delta$, which ultimately restores her desire to retain her, now-expanded, ex post review powers.

Proposition 6 Suppose that the overseer is moderately biased, $\beta \in(1 / 2,-\delta / 2]$ and the extreme state is low urgency, $\delta \in[-2,-1)$. Let $J>0$ be the cost paid by the agent to justify his policy choice following a remand. When $J \in\left(-\delta(\delta+2)-k, \delta^{2}-k\right)$ there is a semi-pooling equilibrium in which the agent chooses $x_{A}=0$ when $\theta \in\{-1,0\}$ :

$$
x_{A}^{*}(\theta)= \begin{cases}0 & \text { if } \theta \in\{0,-1\}, \\ \delta & \text { if } \theta=\delta,\end{cases}
$$


only justifies $x_{A}=\delta$ when he is remanded:

$$
\gamma^{*}\left(x_{A}\right)= \begin{cases}0 & \text { if } x_{A} \in\{0,-1\} \\ 1 & \text { if } x_{A}=\delta\end{cases}
$$

and the overseer upholds $x_{A}=0$, reverses $x_{A}=-1$, and remands $x_{A}=\delta$ :

$$
s_{R}^{*}(x)= \begin{cases}\text { Uphold: } r=0 & \text { if } x_{A}=0, \\ \text { Reverse }: r=1 & \text { if } x_{A}=-1, \\ \text { Remand: } R=1 & \text { if } x_{A}=\delta .\end{cases}
$$

Proof: We construct the equilibrium as follows: first, we hold the overseer's posited equilibrium strategy fixed and show that each of the agent's strategies is a best response; second, we hold the agent's strategies fixed and show that the overseer has no incentive to deviate from her equilibrium strategy. First, consider the agent's decision to justify his policy choice or demur, holding $x_{A}^{*}(\theta)$ fixed.

If the overseer were to remand following $x_{A}(0)=0$ and the agent demurred his payoff would be,

$$
U_{A}\left(\gamma(0)=0 \mid x_{A}^{*}(0)\right)=-(0-(1-1) 0)^{2}-k=-k .
$$

Alternatively, if the agent was remanded and he justified that choice he would receive,

$$
U_{A}\left(\gamma(0)=1 \mid x_{A}^{*}(0)\right)=-(0-(1-0) 0)^{2}-k-J=-k-J .
$$

Clearly, $-k-J<-k$ so the agent is better off not justifying this policy choice.

Now, when $\theta=-1 x_{A}^{*}(-1)=0$ so the analogous payoffs to the agent for demurring and justifying, 
respectively, are given by:

$$
\begin{aligned}
& U_{A}\left(\gamma^{*}(0)=0 \mid x_{A}^{*}(-1)\right)=-(-1-(1-1) 0)^{2}-k=-1-k, \\
& U_{A}\left(\gamma^{*}(0)=1 \mid x_{A}^{*}(-1)\right)=-(-1-(1-0) 0)^{2}-k-J=-1-k-J .
\end{aligned}
$$

Again, since $-1-k>-1-k-J$ the agent optimally demurs in this case.

Finally, when $x_{A}(\delta)=\delta$ the agent's payoffs for demurring and justifying his choice following a remand are given by,

$$
\begin{gathered}
U_{A}\left(\gamma^{*}(\delta)=0 \mid x_{A}^{*}(\delta)=-(\delta-(1-1) \delta)^{2}-k=-\delta^{2}-k\right. \\
U_{A}\left(\gamma^{*}(\delta)=1 \mid x_{A}^{*}(\delta)\right)=-(\delta-(1-0) \delta)^{2}-k-J=-k-J .
\end{gathered}
$$

For the agent to justify his decision in this case the following inequality must hold:

$$
\begin{aligned}
-k-J & >-\delta^{2}-k, \\
\delta^{2} & >J .
\end{aligned}
$$

Provided that $J$ is small enough, the agent optimally justifies his policy choice following remand, given $x_{A}^{*}(\theta)$, only when $x_{A}(\delta)=\delta$. Note that the conditions on $J$ in the result are $J \in\left(-\delta(\delta+2)-k, \delta^{2}-k\right)$. When these conditions are satisfied $J<\delta^{2}$ trivially since $\delta^{2}>\delta^{2}-k$. This yields $\gamma^{*}\left(x_{A}\right)$ as described in the result, given $x_{A}^{*}(\theta)$.

Now we show $x_{A}^{*}(\theta)$ is a best response given $\gamma^{*}\left(x_{A}\right)$ and $s_{R}^{*}\left(x_{A}\right)$. It is straightforward to show that there is no incentive to deviate from $x_{A}(0)=0$. The agent (and overseer) are getting their mostpreferred outcome in this case. Consider the case when $\theta=-1$. If the agent were to truthfully set $x_{A}(-1)=-1$, given off-path overseer beliefs of $\operatorname{Pr}\left[\theta=-1 \mid x_{A}=-1\right]=1$ supporting $s_{R}^{*}\left(x_{A}\right)$, then he will be reversed and his payoff is,

$$
U_{A}\left(x_{A}(-1)=-1 \mid s_{R}^{*}\left(x_{A}\right)\right)=-(-1-(1-1)-1)^{2}-k=-1-k .
$$


If instead the agent chose $x_{A}(-1)=0$ he would be upheld and his payoff is,

$$
U_{A}\left(x_{A}(-1)=0 \mid s_{R}^{*}\left(x_{A}\right)\right)=-(-1-(1-0) 0)^{2}=-1 .
$$

Obviously, the agent prefers to set $x_{A}(-1)=0$ in this case since $-1>-1-k$. The relevant comparison then is whether to set $x_{A}(-1)=0$ or $x_{A}(-1)=\delta$. If $x_{A}(-1)=\delta$ then, given $s_{R}^{*}\left(x_{A}\right)$ the overseer will remand the agent and he will justify his decision. The agent's payoff for $x_{A}(-1)=\delta$ is,

$$
U_{A}\left(x_{A}(-1)=\delta \mid s_{R}^{*}\left(x_{A}\right), \gamma=1\right)=-(-1-(1-0) \delta)^{2}=-(\delta+1)^{2}-k-J\left(=-\delta^{2}-2 \delta-1-k-J\right) .
$$

In order for the agent to prefer $x_{A}(-1)=0$ to $x_{A}(-1)=\delta$ the following inequality must be satisfied:

$$
\begin{aligned}
-1 & >-(\delta+1)^{2}-k-J, \\
J & >-\delta(\delta+2)-k .
\end{aligned}
$$

Thus, if $J$ is large enough then the agent will set $x_{A}(-1)=0$, appeasing the overseer similar to Proposition 2. Note that this derivation yields the lower bound on $J$ to support the stated equilibrium.

Finally, consider $x_{A}^{*}(\delta)=\delta$. In this case, given $s_{R}^{*}\left(x_{A}\right)$ and $\gamma^{*}\left(x_{A}\right)$, the overseer will remand the agent and he will subsequently justify his decision. First, we check for a deviation from $x_{A}^{*}(\delta)=\delta$ to $x_{A}(\delta)=-1$. The agent's payoff for $x_{A}^{*}(\delta)=\delta$ in this case is given by,

$$
U_{A}\left(x_{A}(\delta)=\delta \mid s_{R}^{*}\left(x_{A}\right), \gamma^{*}\left(x_{A}\right)\right)=-(\delta-(1-0) \delta)^{2}-k-J=-k-J .
$$

If instead the agent were to deviate to $x_{A}(\delta)=-1$ his payoff would be,

$$
U_{A}\left(x_{A}(\delta)=-1 \mid s_{R}^{*}\left(x_{A}\right), \gamma^{*}\left(x_{A}\right)\right)=-(\delta-(1-1)-1)^{2}-k=-\delta^{2}-k
$$


So, the agent will set $x_{A}^{*}(\delta)=\delta$ if the following inequality holds,

$$
\begin{aligned}
-k-J & >-\delta^{2}-k, \\
J & <\delta^{2} .
\end{aligned}
$$

Note that this holds trivially since, in the stated equilibrium, $J<\delta^{2}-k$ and $\delta^{2}>\delta^{2}-k$. Thus, the agent will not deviate from his stated equilibrium strategy to $x_{A}(\delta)=-1$. Now consider the agent's payoff from deviating to $x_{A}(\delta)=0$ :

$$
U_{A}\left(x_{A}(\delta)=0 \mid s_{R}^{*}\left(x_{A}\right), \gamma^{*}\left(x_{A}\right)\right)=-(\delta-(1-0) 0)^{2}=-\delta^{2} .
$$

The agent will choose $x_{A}^{*}(\delta)=\delta$ rather than $x_{A}(\delta)=0$ so long as,

$$
\begin{aligned}
-k-J & >-\delta^{2} \\
J & <\delta^{2}-k .
\end{aligned}
$$

Thus, so long as $J$ is not too large, $J<\delta^{2}-k$, then the agent will set $x_{A}^{*}(\delta)=\delta$ as stated in the result. Notice that this derivation yields the upper bound on $J$ that characterizes the equilibrium. Overall, holding $s_{R}^{*}\left(x_{A}\right)$ fixed, so long as $J \in\left(-\delta(\delta+2)-k, \delta^{2}-k\right)$ then the agent's posited strategies $x_{A}^{*}(\theta)$ and $\gamma^{*}\left(x_{A}\right)$ constitute best responses. Since $-\delta(\delta+2)-k<\delta^{2}-k$ for $\delta \in[-2,-1)$ and $k>0$ the interval always has positive measure, implying a $J$ that satisfies these conditions always exists.

To complete the proof of the equilibrium stated in the result we now show that $s_{R}^{*}\left(x_{A}\right)$ is a best response given $x_{A}^{*}(\theta)$ and $\gamma^{*}\left(x_{A}\right)$. Consider first the case in which the overseer observes $x_{A}=0$. In that case, given $x_{A}^{*}(\theta)$, the overseer knows $\theta \in\{0,1\}$. In either case, given appropriate and consistent overseer beliefs, a choice to uphold or reverse leads to the same policy outcome: $x=x_{A}=0$ for $r \in\{0,1\}$. Thus, there is no incentive for the overseer to deviate. Moreover, if the overseer were to remand then the agent would demur (from $\gamma^{*}\left(x_{A}\right)$ ) and, therefore, again $x=0$. Thus, the overseer gains nothing from deviating from the posited strategy of $r(0)=0$.

Now consider the case in which $x_{A}=-1$ (which is off-path). Set the overseer's off-path beliefs 
in this case to $\operatorname{Pr}\left[\theta=-1 \mid x_{A}=-1\right]=1$. Then her payoff for upholding is given by,

$$
U_{R}\left(r=0 \mid x_{A}=-1\right)=-(-1+\beta-(1-0)-1)^{2}=-\beta^{2}
$$

If instead she reverses in this case, her payoff is,

$$
U_{R}\left(r=1 \mid x_{A}=-1\right)=-(-1+\beta-(1-1)-1)^{2}=-(\beta-1)^{2} .
$$

For the overseer to reverse the following inequality must be satisfied:

$$
\begin{aligned}
-(\beta-1)^{2} & >-\beta^{2}, \\
\beta & >\frac{1}{2},
\end{aligned}
$$

which is always satisfied since the overseer has moderate preferences in this case, $\beta \in(1 / 2,-\delta / 2]$. Moreover, if the overseer were to remand then the agent would demur (from $\gamma^{*}\left(x_{A}\right)$ ) and, thus, reversing outright and remanding are payoff-equivalent and there is no reason for the overseer to deviate from reversing to remanding in this case.

Finally, consider the case in which $x_{A}=\delta$. Given $x_{A}^{*}(\theta)$ the overseer knows $\theta=\delta$ in this case. Thus, her payoffs for upholding, reversing, and remanding (given $\gamma^{*}(\delta)$ ) are given by the following expressions, respectively:

$$
\begin{aligned}
U_{R}\left(r=0 \mid x_{A}=\delta\right) & =-(\delta+\beta-(1-0) \delta)^{2}=-\beta^{2}, \\
U_{R}\left(r=1 \mid x_{A}=\delta\right) & =-(\delta+\beta-(1-1) \delta)^{2}=-(\delta+\beta)^{2}, \\
U_{R}\left(R=1 \mid x_{A}=\delta, \gamma^{*}(\delta)\right) & =-(\delta+\beta-(1-0) \delta)^{2}=-\beta^{2} .
\end{aligned}
$$

First, note that $-\beta^{2}>-(\delta+\beta)^{2}$ in this environment so the overseer will never reverse outright. Furthermore, since the payoff for upholding outright and remanding are equivalent the overseer has no incentive to deviate from the posited equilibrium strategy. Thus, the resulting set of analyses constitute the equilibrium characterized in the result. 
Corollary 1 When the review process can be extended as described in Proposition 6, the overseer's preference to retain ex post review is restored (compared to the moderate preferences, low issue urgency environment in Proposition 5).

Proof: This follows straightforwardly from the welfare calculations in the proof of Proposition 5. Specifically, in the equilibrium in Proposition 6, outcomes are equivalent to those when the overseer has moderate preferences and issues are high urgency (Proposition 2). Thus, the overseer's net welfare for retaining ex post review is equivalent to her net welfare for moderate preferences, high urgency issues in part two of Proposition 5. In that case, the overseer strictly prefers to retain ex post review. Thus, it follows that she also prefers to retain review in this environment since both environments are outcome-equivalent.

Lemma 1 Suppose the environment is as described in Proposition 6 and let $c>0$ be the overseer's cost for remanding. Then the equilibrium described in Proposition 6 can no longer be supported.

Proof: To show this we simply show that when remanding costs $c>0$ the overseer prefers to deviate when $x_{A}=\delta$, holding the agent's strategy fixed. From the proof of Proposition 6 we know that the overseer's expected payoff for upholding following $x_{A}=\delta$ is,

$$
U_{R}\left(r=0 \mid x_{A}^{*}(\delta)\right)=-(\delta+\beta-(1-0) \delta)^{2}=-\beta^{2} .
$$

Recall that the overseer's welfare from overturning $x_{A}=\delta$ is given by,

$$
U_{R}\left(r=1 \mid x_{A}^{*}(\delta)\right)=-(\delta+\beta-(1-1) \delta)^{2}=-(\delta+\beta)^{2} .
$$

Clearly, the overseer will always uphold $x_{A}(\delta)=\delta$ in this case since $-\beta>-(\delta+\beta)^{2}$. Thus, the remaining comparison is upholding $x_{A}(\delta)=\delta$ outright or remanding and demanding further justification. The difference from the proof of Proposition 6 is that now $R=1 \operatorname{costs} c>0$. Accordingly, the overseer's expected payoff for remanding in this case is given by (also recalling that the agent 
will justify his choice following remand so that $x=x_{A}(\delta)=\delta$ since $r=0$ is the ultimate disposition),

$$
U_{R}\left(R=1 \mid x_{A}^{*}(\delta), \gamma^{*}(\delta, \delta)\right)=-(\delta+\beta-(1-0) \delta)^{2}-c=-\beta^{2}-c
$$

Clearly, $-\beta^{2}>-\beta^{2}-c$ since $c>0$, implying that the overseer would now deviate to upholding outright. This deviation shows that when remanding is costly the equilibrium in Proposition 6 can no longer be supported, as was to be shown.

\section{A.4 Empirical Predictions Regarding Appeals and Reversals}

This recognition makes the empirical implications of the theoretical prediction concrete because, in this case, the agent is reversed on the equilibrium path only if he recommends the significant policy change $\left(x_{A}=\delta\right)$. Thus, in equilibrium, the overseer engages in meaningful review only when $x_{A} \neq 0$. Or put another way, an (unmodeled) potential litigant/petitioner of the overseer would seek relief only when $x_{A}=\delta$ or $x_{A}=-1$. Given this, we can define the probability of a challenge to the agent's decision, $C(p, \beta, \delta)$, as follows:

$$
\begin{aligned}
C(p, \beta, \delta) & \equiv p_{\delta}+p_{-1} \frac{p_{\delta}(2 \beta+\delta)}{p_{-1}(\delta-2 \beta+2)} \\
& =p_{\delta}\left(\frac{2(1+\delta)}{\delta-2 \beta+2}\right) .
\end{aligned}
$$

Equation (7) represents the equilibrium probability that the agent chooses $x_{A}=\delta$, because he never

chooses $x_{A}=-1$ in the equilibrium we are examining. Combining this with the overseer's review strategy when the agent pursues policy change (from Proposition 4):

$$
\rho(\delta, k)=\frac{2 \delta+\delta^{2}}{2 \delta+\delta^{2}-k}
$$

we obtain the ex ante probability of a reversal, which we denote by $R(p, \beta, \delta, k)$ :

$$
R(p, \beta, \delta, k) \equiv C(p, \beta, \delta) \cdot \rho(\delta, k)=p_{\delta}\left(\frac{2(1+\delta)}{\delta-2 \beta+2}\right) \frac{2 \delta+\delta^{2}}{2 \delta+\delta^{2}-k}
$$

$R(p, \beta, \delta, k)$ gives us the likelihood an agent will be reversed when the overseer has moderate 
preferences and the extreme state is relatively less likely. This depends on how likely it is that the agent will be challenged, which further depends on how likely it is the agent will pursue extreme policy change, and how likely it is the overseer will reverse the agent following such a change to policy. The agent pursues extreme policy change when the policy environment calls for it $(\theta=\delta)$ and with positive probability when the state calls for moderate policy change $(\theta=-1)$ because he is crying wolf. The overseer reverses the agent with positive probability following such policymaking behavior, but will sometimes uphold the agent since the agent could be sincerely pursuing extreme policy change rather than simply crying wolf. We now turn to empirical implications that speak to how key parameters of the model alter the nature of policy change and reversals.

The Effect of the Overseer's Preferences, $\boldsymbol{\beta}$. We first consider how the overseer's preferences affect policy choices and both the ex ante and conditional probabilities of the agent being reversed. Notice that the ex ante probability of observing a reversal, $R(p, \beta, \delta, k)$ is decreasing in $\beta$ :

$$
\frac{\partial R(p, \beta, \delta, k)}{\partial \beta}=2 p_{\delta}\left(\frac{2(1+\delta)}{(\delta-2 \beta+2)^{2}}\right) \frac{2 \delta+\delta^{2}}{2 \delta+\delta^{2}-k}<0
$$

but the conditional probability of being reversed, $\rho(\delta, k)$, is invariant to $\beta$ : $\frac{\partial \rho(\delta, k)}{\partial \beta}=0 .{ }^{35}$ Thus, the ex ante probability of the agent being reversed decreases as the overseer's preferences become more extreme, but the agent's success when challenged is unaffected by changes in the overseer's preferences. These points are summarized in the following prediction.

Prediction 1 If reversals occur with positive probability, then the agent will choose the extreme policy and face challenge less frequently when the overseer's preferences become more extreme (i.e. for larger values of $\beta$ ). However, the conditional probability that the agent is reversed will be independent of the overseer's preferences. The logic behind Prediction 1 is intuitive: as the overseer's preferences become more extreme, the overseer remains indifferent about reversing the extreme policy only if the conditional probability that the agent is truthful when it chooses the extreme policy increases. Put another way, as the overseer's preferences become more extreme, she is willing to incur a larger probability of "incorrectly" reversing the agent (i.e., $r=1$ when $\theta=\delta$ )

\footnotetext{
${ }^{35}$ Of course, the fact that $\rho(\delta, k)$ is not affected by $\beta$ is a consequence of mixed strategy equilibria.
} 
in pursuit of "correctly" reversing (i.e., $r=1$ when $\theta=-1$ ). In response, the agent reduces the probability that he cries wolf and increases the probability he pursues no policy change at all when $\theta=-1$. That is,

The Effect of the Agent's Aversion to Reversal, $k$. The agent's conditional probability of reversal after choosing $x_{A}=\delta, \rho(\delta, k)$, is a function of his reversal aversion, $k$. Furthermore, inspection of equation (7) reveals that the agent's own behavior (i.e., the probability that he chooses the extreme policy and provokes challenge/review) is independent of his aversion to reversal. Because $\rho(\delta, k)$ is a decreasing function of $k$, we obtain the following prediction.

Prediction 2 If reversals occur with positive probability, then agents that find reversal less punitive ( $k$ closer to zero) will be reversed more often. However, the frequency with which the agent is challenged will be independent of $k$.

The Effect of the Urgency of the Policy Area, $\delta$. Changing $\delta$ is equivalent to altering the importance of the "extreme state": when $\delta$ is larger in absolute value, both the agent and the overseer have a stronger preference for truthful policymaking. In other words, both the overseer and the agent incur a larger cost from reversal and obfuscation by the agent when he chooses $x_{A}=\delta$ when $\theta=-1$. The conditional probability of reversal, $\rho(\delta, k)$, is a decreasing function of the urgency of the policy change (i.e., $|\delta|)$, leading to the following prediction.

Prediction 3 If reversals occur with positive probability then, conditional on proposing a policy change (i.e., $x_{A} \neq 0$ ), agents will be reversed more often on lower urgency issues ( $\delta$ closer to -1$)$.

Viewed broadly from an empirical standpoint, Prediction 3 suggests that, conditional upon reviewing an agent's decision, the overseer will appear to be more deferential both to decisions regarding policies with greater uncertainty and to more extreme policy changes. We saw above in the welfare analysis that this correlation can generate an incentive for the overseer to abandon ex post review, particularly once paired with the following fact: the probability the agent proposes a policy change is increasing in the urgency of the extreme state, $\delta$, as stated in the following prediction.

Prediction 4 If reversals occur with positive probability, then the probability that the agent proposes a policy change (i.e., $\left.x_{A} \neq 0\right)$ is higher for higher urgency issues $(\delta$ closer to $-2 \beta)$. 